\title{
Intraarterial transplantation of human umbilical cord blood mononuclear cells is more efficacious and safer compared with umbilical cord mesenchymal stromal cells in a rodent stroke model
}

\author{
Neha Karlupia ${ }^{1,2,3^{*}}$, Nathan C Manley ${ }^{1,2}$, Kameshwar Prasad ${ }^{3}$, Richard Schäfer ${ }^{1+}$ and Gary K Steinberg ${ }^{1,2^{*}+}$
}

\begin{abstract}
Introduction: Stroke is the second leading cause of death worldwide, claims six lives every 60 seconds, and is a leading cause of adult disability across the globe. Tissue plasminogen activator, the only United States Food and Drug Administration (FDA)-approved drug currently available, has a narrow therapeutic time window of less than 5 hours. In the past decade, cells derived from the human umbilical cord (HUC) have emerged as a potential therapeutic alternative for stroke; however, the most effective HUC-derived cell population remains unknown.

Methods: We compared three cell populations derived from the human umbilical cord: cord blood mononuclear cells (cbMNCs); cord blood mesenchymal stromal cells (cbMSCs), a subpopulation of cbMNCs; and cord matrix MSCs (cmMSCs). We characterized these cells in vitro with flow cytometry and assessed the cells' in vivo efficacy in a 2-hour transient middle cerebral artery occlusion (MCAo) rat model of stroke. cbMNCs, cbMSCs, and cmMSCs were each transplanted intraarterially at 24 hours after stroke.

Results: A reduction in neurologic deficit and infarct area was observed in all three cell groups; however, this reduction was significantly enhanced in the cbMNC group compared with the cmMSC group. At 2 weeks after stroke, human nuclei-positive cells were present in the ischemic hemispheres of immunocompetent stroke rats in all three cell groups. Significantly decreased expression of rat brain-derived neurotrophic factor mRNA was observed in the ischemic hemispheres of all three cell-treated and phosphate-buffered saline (PBS) group animals compared with sham animals, although the decrease was least in cbMNC-treated animals. Significantly decreased expression of rat interleukin (IL)-2 mRNA and IL-6 mRNA was seen only in the cbMSC group. Notably, more severe complications (death, eye inflammation) were observed in the cmMSC group compared with the cbMNC and cbMSC groups.
\end{abstract}

Conclusions: All three tested cell types promoted recovery after stroke, but cbMNCs showed enhanced recovery and fewer complications compared with cmMSCs.

\footnotetext{
* Correspondence: neha.karlupia@gmail.com; gsteinberg@stanford.edu

${ }^{\dagger}$ Equal contributors

'Department of Neurosurgery, R281, Stanford School of Medicine, Stanford

University, Stanford, CA 94305-5487, USA

${ }^{2}$ Stanford Stroke Center, Stanford University School of Medicine, Stanford

University, Stanford, CA 94305, USA

Full list of author information is available at the end of the article
} 


\section{Introduction}

Cells derived from the human umbilical cord (HUC) have been successfully used in the clinic for almost 2 decades [1-4]. Their simple and economic retrieval, enrichment for hematopoietic progenitors, enhanced proliferation rate, expansion potential $[5,6]$, and low incidence of graft-versushost disease $[7,8]$ makes them a promising cell treatment for several disorders. Although their therapeutic benefits were initially thought to be limited to hematopoietic disorders, several recent studies have shown the potential of these HUC-derived cells to enhance regeneration and tissue repair in various pathological disorders, including neurologic diseases [9-11]. HUC-derived cells have already been used clinically for nonhematopoietic degenerative conditions [12], hereditary ataxia [13], and disorders such as cerebral palsy [14] and spinal cord injury [15], and they are currently being tested for neonatal hypoxic-ischemic encephalopathy (clinicaltrials.gov/ct2/show/NCT00593242).

HUC-derived cells have been used in preclinical stroke studies for more than a decade. Alhough most studies have shown significant functional or histo-pathologic recovery, homing, and differentiation of the grafted cells [16-25], some studies reported on lack of migration or neurologic benefits [26-28] or absence of human nucleipositive cells despite evidence of functional recovery [29]. In a meta-analysis, we assessed the effects of HUC-derived cells in preclinical stroke studies (included studies, 14). We found a significant reduction in infarct volume with an overall effect of $\mathrm{Z}=6.54(P<0.00001)$, with a noticeable heterogeneity as well $\left(I^{2}=87 \%\right)$. Apart from variation in study design, cell dose, or route of transplantation, a possible source of this heterogeneic outcome could be the varying mix of cell populations present in human umbilical cord blood [11] and/or biologic differences of the cord matrix/blood-derived cell populations used in these studies. cbMNCs comprise a heterogeneous mix of immature lymphocytes, monocytes [12,30], hematopoietic [31], endothelial [32], and mesenchymal [33-36] stem/progenitor cells. Moreover, studies report on the presence of very small embryonic-like stem cells [37], embryonic-like cells [38,39], and neural stem/progenitor cells [40-42] at different lineage commitment stages. It is therefore important to understand whether it is the mixture of cord blood cells or a specific stem cell population that is responsible for ameliorating the harmful effects of stroke and hereby to assess the risks of cell therapy.

In this study, we characterized and compared cbMNCs from HUCs with two entities of HUC-derived mesenchymal stromal cells (MSCs): cord blood MSCs (cbMSCs), and cord matrix MSCs (cmMSCs). Whereas cbMSCs are composed of a rare population of multipotent precursors enriched from cbMNCs [35,43,44], cmMSCs are derived from the mucoid connective tissue surrounding cord blood vessels, known as Wharton jelly [45]. These three cell populations were transplanted into stroke rats to assess their potential effects on recovery and their ability to home to the host brain after intraarterial transplantation. Additionally, we analyzed the inflammatory response in the host, as well as the expression of brain-derived neurotrophic factor (BDNF), epidermal growth factor (EGF), glutathione peroxidase-4 (GPx-4), and reelin mRNA in the ipsilateral hemispheres of the study animals, given their role in neuroprotection and recovery after stroke [46-56].

\section{Materials and methods}

Transient middle cerebral artery occlusion model and sham surgery

All animal procedures were approved by the Stanford University Administrative Panel on Laboratory Animal Care. Adult male Wistar rats (270 to $300 \mathrm{~g}$ ) were subjected to middle cerebral artery occlusion (MCAo) by using the 2-hour transient intraluminal filament occlusion model of cerebral ischemia, as described previously $[49,57,58]$. In brief, rats were anesthetized with $2 \%$ isoflurane in a mixture of $30 \%$ oxygen and $70 \%$ air. After a midline incision, the right common carotid artery (CCA), external carotid artery (ECA), and internal carotid artery (ICA) were exposed. The CCA and ICA were temporarily ligated, and a 4-0 silicone rubber-coated reusable monofilament (Doccol Inc, 40SPRe3756) was inserted into the lumen of the right ICA through a small incision in the ECA. The filament was advanced into the ICA until 18 to $19 \mathrm{~mm}$ was inserted from the bifurcation, and the origin of the middle cerebral artery was blocked. Physiological parameters (respiratory rate, core body temperature, and color of mucous membranes) were monitored and recorded throughout the surgical procedure. Two hours after the MCAo, each animal was reanesthetized, and the monofilament was withdrawn to cause reperfusion. All surgery animals were given analgesic treatment with 0.03 $\mathrm{mg} / \mathrm{kg}$ buprenorphine.

For sham surgery, the ECA was surgically prepared for insertion of the filament, but the 4-0 monofilament was not inserted. The neck incision was closed, and each animal underwent the same postoperative care as the stroke surgery animals.

\section{Isolation of cbMNCs and culture of MSCs}

Cord blood collection was approved by the Institutional Review Board (IRB) and Stem Cell Research Oversight (SCRO) Committee at Stanford University. Informed consent was taken from donor mothers before samples were collected. All six cord-blood samples were processed within 10 hours of collection, and cbMNCs were obtained by using the Ficoll-Paque density gradient method $[40,59,60]$. Cell viability was tested by using the trypan blue exclusion method. The cbMNCs obtained were used for cbMSC culture, flow-cytometry 
experiments, transplantation, or cryopreservation. cbMSC cultures were established, as previously described [61], with modifications made in our laboratory. In brief, $60 \times$ $10^{6}$ cbMNCs were plated per fibronectin-coated six-well plates (Nunc, Thermo Fisher Scientific, Waltham, MA, USA) in proliferation medium comprising MEM- $\alpha$ with glutamax, ribonucleosides, and deoxyribonucleosides (Invitrogen, Grand Island, NY 16000-044), 10\% fetal bovine serum (Gibco FBS), $50 \mathrm{n} M$ dexamethasone (SigmaAldrich, St. Louis, MO D8893), $10 \mathrm{ng} / \mathrm{ml}$ epidermal growth factor (Sigma-Aldrich E9644), $10 \mathrm{ng} / \mathrm{ml}$ plateletderived growth factor (R\&D Systems, Minneapolis, MN), and 1× penicillin-streptomycin (Invitrogen 15140-122). Plates were placed in a normoxic humidified incubator with $5 \% \mathrm{CO}_{2}$ and growth medium was replaced after 24 hours of plating and every alternate day thereafter.

On appearance of the first colony of adherent cells, cells were harvested by using $0.25 \%$ trypsin-EDTA solution and re-plated in new noncoated culture plates. Passages 5 to 6 were used in all experimental procedures. cmMSCs were obtained commercially from PromoCell (C-12971, Germany) and were expanded by using proliferation medium (C-28010, PromoCell).

\section{Flow-cytometry analysis}

Flow cytometry was used to characterize the cultured cbMSCs and to compare them with cbMNCs and cmMSCs. cbMSCs from passages 5 and 6 were assessed for expression of mesenchymal and hematopoietic lineage markers relative to cbMNCs in successive flow-cytometry experiments by using mouse anti-human CD73 (PE), CD90 (FITC), CD166 (PE), CD34 (FITC), CD133 (APC), CD19 (FITC), CD45 (APC-Cy7), HLA-ABC (FITC), and HLA-DR (FITC). cbMSCs were further compared with cmMSCs and cbMNCs simultaneously by using a multicolor flow-cytometry experiment designed for a total of 27 phenotypic markers (see Additional file 1). cbMSCs and cmMSCs used in this experiment were from passage 6, and cbMNCs used were from the same sample from which the cbMSC culture was established. For comparative immunophenotyping, cbMNCs, cbMSCs, and cmMSCs (75,000 cells per experiment) were washed with phosphatebuffered saline (PBS) containing $0.1 \%$ to $1 \%$ FBS, and $100-\mu \mathrm{l}$ aliquots of each were placed in flow-activated cell sorting (FACS) tubes for staining.

Six antibody cocktails (Additional file 1) were used for characterization of the three cell types and were prepared according to their conjugated fluorochromes and their emission ranges. The volume of each antibody used was per manufacturer's recommendation or as titrated in preliminary experiments. Antibody cocktails were added to each tube and incubated at $4^{\circ} \mathrm{C}$ for 30 minutes. Stained cells were given three washes at $1,200 \mathrm{rpm}$ for 5 minutes each and then suspended in $500 \mu \mathrm{l}$ FACS buffer. Simultaneously, compensation controls were prepared for all the markers by using BD-CompBeads (BD Biosciences, San Jose, CA). Flow cytometry was performed on a Becton Dickinson LSR-II (Stanford Shared FACS Facility), and data were analyzed with FlowJo (TreeStar Inc). Gates were set according to the unstained and 7-amino-actinomycin D-stained controls to exclude dead cells for each cell type, and compensation was done by single-color-stained BD-CompBeads. Isotype controls were not used for these experiments, as several past studies pointed to their nonessential [62-64] or potentially misleading results $[65,66]$.

\section{Transplantation of cbMNCs, cbMSCs, or cmMSCs}

Animals were randomly divided into experimental groups: sham surgery $(n=12)$; MCAo + PBS $(n=27)$; MCAo rats infused with $10 \times 10^{6}$ cbMNCs $(n=24) ; 5 \times 10^{6}$ cbMSCs $(n=18) ; 5 \times 10^{6} \mathrm{cmMSCs}(n=23)$, and $10 \times 10^{6} \mathrm{cmMSCs}$ $(n=6)$. Stroke animals were injected with PBS or cells suspended in PBS 24 hours after stroke through an intracarotid route. To assess the inflammatory reaction after stroke, none of the experimental animals received an immunosuppressant drug.

\section{Assessment of neurologic deficit}

The rotarod, grid-walk, and open-field behavior tests were used to assess motor coordination, sensory motor function, and spontaneous activity of study animals before surgery (MCAo/sham), and at 1, 4, 7, and 14 days after surgery. Baseline readings at 24 hours before surgery were the internal controls for each study animal. All behavior experiments were performed between 9 AM and 2 PM.

In the rotarod performance test rats were placed on a motor-driven cylinder and the length of time they remained on it before falling was recorded $[16,67,68]$. Animals were trained 3 days before surgery to remain on the rotating spindle (moving at a constant speed of 8 $\mathrm{rpm}$ ) for 60 seconds. One day before surgery, the trained animals were given a test trial on an accelerating cylinder (with an increasing speed of 4 to $40 \mathrm{rpm}$ within 5 minutes), and latency to their fall was recorded.

The grid-walk test was modified from the test described by Rogers et al. [68]. Rats were placed on an elevated $30-\mathrm{mm}^{2}$ grid floor for 1 minute to be acclimated and then placed on the grid floor and recorded for $2 \mathrm{mi}-$ nutes. Total numbers of paired steps as well as total numbers of foot faults for each limb were manually counted from the recorded videos [67]. Percentage foot fault was determined by using the formula: ((Number of foot faults/ (number of paired steps + number of foot faults)) $\times 100$ ).

For the open-field test, animals were individually placed in the center of the arena and were tracked with a video camera connected to a computer. Ethovision XT 5.1 software by Noldus was used to design the paradigm 
for recording, and animals were recorded for 10 minutes for each trial. Total distance moved by each animal during the 10-minute trial was compared to assess spontaneous activity.

\section{Assessment of infarct size}

On day 14 after stroke, rats were killed with isoflurane and perfused transcardially with $0.1 M$ PBS ( $\mathrm{pH} 7.4$ ) followed by $4 \%$ paraformaldehyde (PFA). Brains were extracted and incubated overnight in 10-fold 4\% PFA and were saturated with increasing sucrose concentrations (20\% followed by $30 \%$ ) in PBS for 24 to 48 hours. Cryosections $(20 \mu \mathrm{m})$ were cut serially between +1 to -1 bregma. Seven coronal sections (200 $\mu \mathrm{m}$ apart) per brain were stained by using high-contrast silver staining and scanned at 1,200 dpi $[69,70]$. Image $\mathrm{J}$ software by the National Institutes of Health (NIH) was used to measure the total ipsilateral, contralateral, and infarct areas. Infarct area was calculated relative to the contralateral hemisphere by using the formula: infarct size $=100 \times($ total contralateral hemisphere area - (total ipsilateral hemisphere area-infarct area)/total contralateral hemisphere area) $[17,69]$.

\section{Tissue processing and immunohistochemistry}

At 2 weeks after stroke, animals were transcardially perfused, and brains were extracted and sectioned at $20-\mu \mathrm{m}$ postfixation. Immunohistochemistry was performed for localization of human nuclei $(\mathrm{HuNu})$-positive cells in celltreated animals and to assess the effect of transplanted cells on immune response by using anti-CD68 and ionized calcium-binding adapter molecule-1 (Iba-1) antibodies.

Immunohistochemistry to localize transplanted human cells was performed [71] by using a monoclonal antibody specific for human nuclei with no cross-reactivity for rat or mouse nuclei (MAB1281, mouse anti-HuNu, Millipore, Billerica, MA). In brief, endogenous peroxidase activity was quenched with $\mathrm{H}_{2} \mathrm{O}_{2}(0.3 \%)$, and sections were blocked for 40 minutes in tris-buffered saline (TBS) containing 5\% normal goat serum (NGS; Vector Laboratories, Burlingame, CA, S-1000). Sections were incubated overnight at $4^{\circ} \mathrm{C}$ with primary antibody (1:100) and then incubated with biotinylated secondary antibody (goat anti-mouse IgG, Zymed; Vector Laboratories, 1:200) for 2 hours at room temperature followed by $\mathrm{ABC}$ (Vectastain Elite; Vector Laboratories) and diaminobenzidine (DAB; Vector Laboratories) developing. Immunohistochemical staining in the contralateral hemisphere was used as an internal control for each animal. Sections from the PBS-group animals were also stained as a negative control for human cells.

A similar procedure was followed with the lysosomal marker CD68 by using mouse monoclonal anti-rat CD68 antibody (sc-59103; Santa Cruz Biotechnology, Inc., Santa Cruz, CA, 1:200).
For Iba-1, immunofluorescence was performed. Primary antibody (rabbit anti-Iba-1; Wako; 1:600) was incubated overnight at $4^{\circ} \mathrm{C}$ followed by 2 hours of incubation at room temperature with secondary antibody diluted at 1:400 (Alexa Fluor-594 goat anti-rabbit; Invitrogen, Life Technologies, Grand Island, NY-A11037) [71]. Mounting was done by using Vectashield mounting media with DAPI (Vector Laboratories, H-1200), and images were taken by using a Zeiss fluorescence microscope.

\section{Total RNA isolation, reverse transcription, and quantitative real-time PCR}

Total RNA was isolated by using the Qiagen RNeasy Mini Kit and following manufacturer's instructions. In brief, rats were killed at day 14, and the brains were extracted. About $3 \mathrm{~mm}^{3}$ (approximately $30 \mathrm{mg}$ ) of tissue was excised from the ischemic hemisphere, 2 to -1.5 bregma, and just medial to the infarcted region of cell-treated and PBS-group animals. A similarly representative brain region was excised from the ipsilateral hemisphere of sham animals. Reverse transcriptase reactions were performed with the Bio-Rad iScript cDNA synthesis kit by using $1 \mu \mathrm{g}$ of total RNA.

To analyze levels of mRNA, qPCR was performed on the Bio-Rad CFX96 Real-Time Detection System by using Taqman gene-expression assays (Inventoried/Cat. 4331182; Applied Biosystems, Carlsbad, CA, USA) according to the manufacturer's instructions. Reference genes were rat- and human-specific glyceraldehyde-3-phosphate dehydrogenase (GAPDH) (Rn01775763_g1; Hs03929097_g1*). Target genes were rat-specific brain-derived neurotrophic factor (BDNF) (Rn02531967_m1); glutathione peroxidase-4 (GPx-4) (Rn00 820816_g1); epidermal growth factor (EGF) (Rn005633 36_m1); reelin (Rn00589609_m1); interleukin 1beta (IL-1ß) (Rn00580432_m1); tumor necrosis factor alpha (TNF-A) (Rn01525859_g1); rat- and human-specific interleukin (IL)2 (Rn00587673_m1, Hs00174114_m1); IL-6 (Rn014103 30_ml, Hs00985639_m1); and IL-10 (Rn0053409_m1, Hs00 961622_m1).

The threshold cycles $(\mathrm{Ct})$ for the target gene and internal control were determined for each sample, which underwent $\mathrm{qPCR}$ in parallel duplicate runs. Expression of target genes was normalized to the housekeeping gene $G A P D H$ and is displayed as $2^{-\triangle C T}$.

\section{Assessment of adverse effects and mortality rate}

Appearance of adverse effects during/within 24 hours and 24 hours after cell administration was recorded. The total of dead animals in each group was counted separately for time points $<24$ hours and $>24$ hours after transplantation. The mortality rate was calculated as percentage of animals that died of total animals in each group. Statistical significance for mortality was calculated relative to $\mathrm{PBS}$ group. 


\section{Statistics}

Statistical analyses of data were performed with GraphPad Prism 5 software (San Diego, CA, USA). One-way analysis of variance (ANOVA) with Tukey post hoc test was used for percentage of infarct area, and two-way ANOVA (with Bonferroni post hoc test) was used for behavioral analysis. The $t$ test with Bonferroni multiplecomparison adjustment was used for qPCR analysis. All neurologic, histopathologic, and gene-analysis data are presented as mean \pm SEM. For flow-cytometry data analysis, the two-tailed $t$ test with Welch correction was used, and data are presented as mean \pm SD. For mortality data analysis, the Fisher Exact test was used with twotailed $P$ values. Significance was set at $P<0.05$.

\section{Results}

Culture of cbMSCs and comparative immunophenotyping of cbMNCs, cbMSCs, and cmMSCs with flow cytometry

Attempts to isolate MSCs from six cord-blood samples resulted in two colonies of adherent cells that showed a flat, spindle-shaped, fibroblastoid phenotype (Figure 1). The first colony from these two cord blood samples was visible at days 16 and 18, respectively. Cultured cbMSCs were assessed at passages 5 and 6 for the expression of surface antigens reportedly expressed on MSCs [72], and were found positive for CD90, CD73, CD166, and showed negligible expression of CD45 and HLA-DR. Relative to cbMNCs, enriched cbMSCs showed higher expression of CD73, CD166 $(P<0.0001)$, CD90 $(P<0.0004)$ and decreased expression of HLA-DR $(P<0.0001)$, CD45 $(P<0.01)$, and CD19 $(P<0.005)$ (Figure 1A,B).

Enriched cbMSCs showed a trend toward higher expression of HLA-ABC and lower expression of CD34 and CD133. CbMSCs were compared with cbMNCs and commercially obtained matrix-derived cmMSCs by using multicolor flow cytometry (Table 1; see Additional files 2, 3). cbMNCs were positive for MHC I, MHC II, dendritic, hematopoietic, leukocytic, endothelial, lymphocytic, and myeloid cell markers (CD56, CD14, CD45, LIN1, CD33), but, like $\mathrm{cb} / \mathrm{cmMSCs}$, showed very low expression of primitive hematopoietic progenitors (CD34, CD133). Both cbMSCs and cmMSCs were highly positive for CD44, CD117, CD73, CD166, CD184, CD59, CD123, and CD210, and showed very low expression of HLA-DR, CD34, CD33, CD133, and CD45. Apart from the expression of MSC lineage markers, expression of CD117 (stem cell factor), CD184 (CXCR4 receptor), CD106 (VCAM-1 molecule), CD59 (inhibitor of membrane attack complex formation), and lack of $\mathrm{Lin}^{+}$cells (only in cbMSCs), mainly distinguished MSCs from cbMNCs (Table 1 and Additional files 2, 3).

Although cmMSCs expressed typical MSC markers, these cells also exhibited expression of certain markers (Lin $1^{+} 31.6 \%$ compared with $0.46 \%$ for cbMSCs; CD56,
$80 \%$ compared with $1.28 \%$ for cbMSCs; CD4, 68\% compared with $5.8 \%$ for cbMSCs and CD14, 20\% compared with $0.404 \%$ in cbMSCs), similar to cbMNCs. CD56, expressed on neuronal and NK cells and known to mediate synaptic plasticity, was found highest in cmMSCs (80.8\%) compared with $11.3 \%$ in cbMNCs and $1.28 \%$ in cbMSCs.

\section{cbMNCs are as effective as cbMSCs or cmMSCs in improving motor coordination}

Compared with the PBS group, all three cell-group animals showed significant recovery in the rotarod test at day 4 $(P<0.01$ for MNC and $P<0.05$ for cbMSC and cmMSC), which continued until day 14 after stroke $(P<0.001$, cbMNC; $P<0.01$, cbMSC and cmMSC). At 24 hours after stroke, the latency to fall from the rotating spindle was significantly shorter in MCAo versus sham animals; however, no significant differences were seen in the sham-versus-cell groups or within the three cell-treated groups at days 4, 7 and 14. By 2 weeks, all three cell groups were performing at prestroke baseline levels (Figure 2A).

\section{cbMNCs and cbMSCs but not cmMSCs promote improvement in spontaneous activity after stroke}

MCAo caused a significant decrease in spontaneous activity of stroke rats compared with the sham group at day 1 . Improvement in spontaneous activity, although not significant, was seen at day 4 after stroke in cell-treated animals and at day 7 in PBS-group animals. Despite continuous improvement in the spontaneous activity of cell-treated rats from days 4 to 14 , significant recovery relative to the PBS group was seen only at day 14 after stroke in the cbMNC and cbMSC groups but not in the cmMSC group. PBS-treated MCAo rats showed increased spontaneous activity at day 7 , which showed a deteriorating trend at day 14. No significant difference was seen across the three cell groups (Figure 2B).

\section{cbMNCs are more effective in reducing sensory-motor deficits than are cbMSCs or cmMSCs}

All study animals showed similar limb misplacements in the grid-walking test before stroke, which increased significantly after stroke relative to the sham group. Compared with the PBS group, all cell-treated animals showed a decreasing trend in percentage of foot faults, starting on day 4 (Figure $2 \mathrm{C}$ ). However, only the cbMNC and cbMSC groups showed significant reductions in limb misplacement at day 14 after stroke $(P<0.001$ for cbMNCs and $P<0.01$ for cbMSCs) compared with the PBS group. Only the cbMNC group showed significant reduction in foot faults starting on day $7(P<0.01)$ and, by day 14, percentage of foot faults in this group was as low as prestroke baseline values. At day 14, the cbMNC group performed significantly better than the cmMSC 


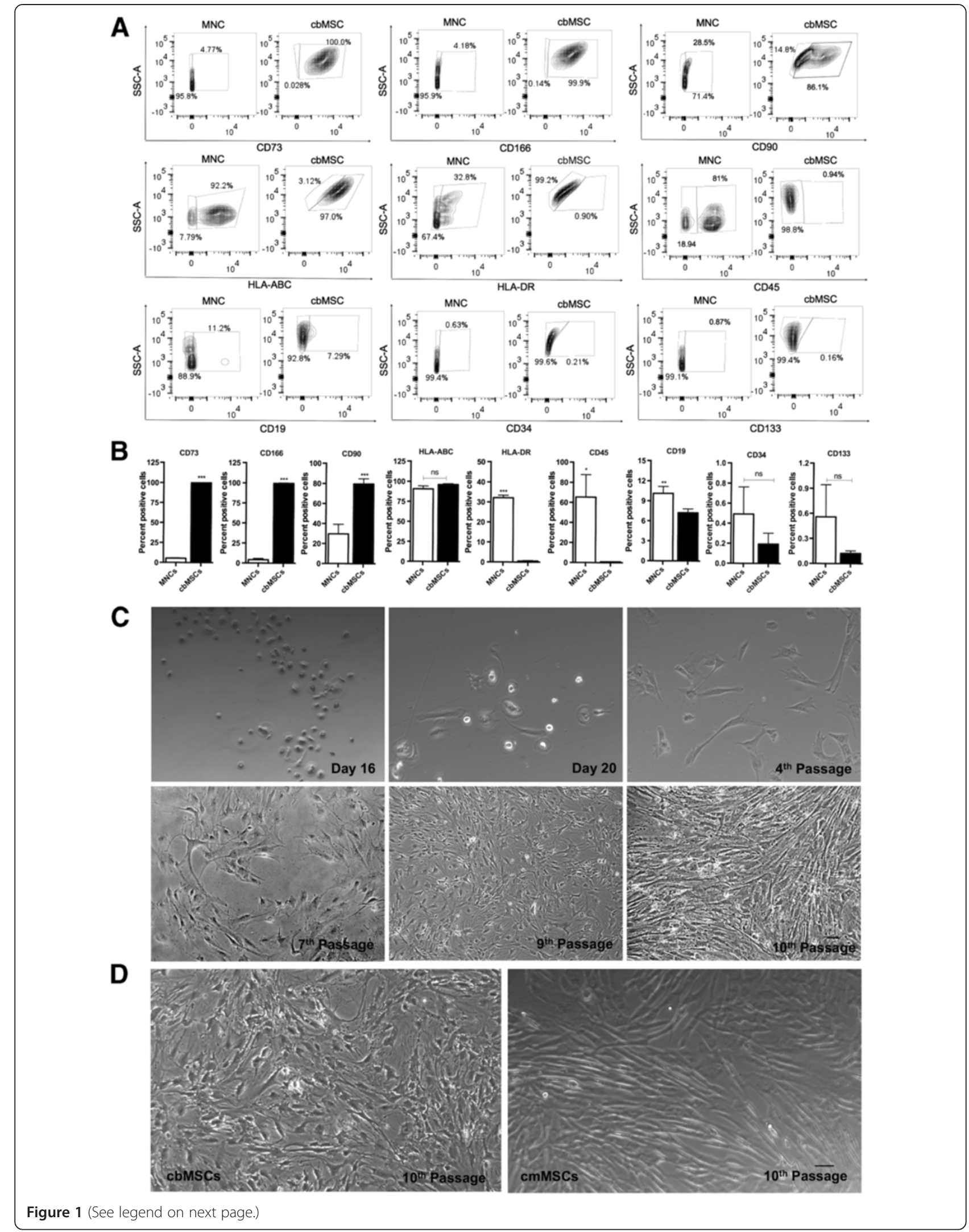


(See figure on previous page.)

Figure 1 Immunophenotypic characterization and expansion of cultured cord-blood MSCs. Culturing cbMSCs from cbMNCs resulted in enrichment of $\mathrm{CD} 73^{+} \mathrm{CD} 166^{+} \mathrm{CD} 90^{+} \mathrm{CD} 45^{-} \mathrm{CD} 34^{-} \mathrm{HLA}-\mathrm{DR} \mathrm{R}^{-}$cells closely resembling the phenotypes of MSC proposed by the International Society for Cellular Therapy (ISCT), 2006 [72]. Representative flow-cytometry contour plots are shown to illustrate expression of individual phenotypic markers in cbMNCs and cbMSCs (A). In each plot, percentage of cells positive for a given marker is shown on the right, and percentage of cells negative for the same marker is shown on the left. Relative to cbMNCs, cbMSCs had enriched expression of CD73, CD166 ( $<<0.0001)$, CD90 $(P<0.0004)$, and decreased expression of HLA-DR $(P<0.0001)$, CD45 $(P<0.01)$, and CD19 $(P<0.005)$. cbMSCs also had relatively higher expression of HLA-ABC and lower expression of CD34 and CD133, although the difference was not significant (B). Spindle-shaped, fibroblast-like, flat, adherent cells are shown across various passages of cbMSC culture (magnification 10x) (C). Comparative morphologic representation of 10th passage cbMSCs and commercially obtained cmMSCs is shown in (D). Student $t$ test, $n=4$ for each group, $\left(^{* *}\right)$ is $P<0.01$, $\left(^{* * *}\right)$ is $P<0.001$, and (ns) is nonsignificant. Data represent means \pm SD.

group $(P<0.05)$, but there was no significant difference between cbMSC and cmMSC groups.

A subgroup analysis ( $n=8$ per group) showed significant recovery in both contralateral forelimb and hindlimb function of cbMNC-treated animals and only contralateral hindlimb function of cbMSC-group animals compared with PBS-group animals (Figure 2D,E). cbMNC-group animals displayed significantly fewer faults in the contralateral forelimb at day $4(P<0.01)$ and at days 7 and 14 $(P<0.05)$, compared with PBS-group animals, (Figure 2D). Both cbMNC- and cbMSC-group animals had significant reduction in contralateral hindlimb misplacement at day 14 after stroke $(P<0.05$ for $\mathrm{MNC}$ and $P<0.01$ for cbMSC group), relative to $\mathrm{PBS}$ group (Figure $2 \mathrm{E}$ ).

\section{cbMNCs promote greater reduction in infarct size}

High-contrast silver staining at day 14 after stroke showed extensive cortical and striatal atrophy, massive loss of cytoarchitecture, and enhanced ventricular enlargement in the PBS group. Transplantation of all three cell types significantly reduced infarct size with apparently reduced ventricular enlargement and loss of cytoarchitecture. The percentage of infarct area, calculated relative to the contralateral hemisphere, was $62.337 \% \pm 5.508 \%$ in the PBS group, $42.64 \% \pm 6.56 \%$ in the cbMNC group, $46.436 \% \pm$ $6.3 \%$ in the cbMSC group, and $51.337 \% \pm 4.37 \%$ in the cmMSC group, $(n=10$ per group). Although all three cell types were similarly effective in reducing infarct size relative to the PBS group $(P<0.001)$, the reduction in percentage infarct area was significantly greater in the cbMNC group compared with the cmMSC group $(P<0.01)$ (Figure 3B). No significant difference was seen in percentage of infarct area of cbMNC and cbMSC groups or between cbMSC and cmMSC groups.

\section{cbMNCs, cbMSCs, and cmMSCs can survive in the host ischemic environment and mediate similar immunomodulatory effects}

To identify and characterize the transplanted human cells in the brains of immunocompetent stroke rats, immunohistochemistry was performed on coronal brain sections at 2 weeks after transplantation ( $n=4$ per group).
$\mathrm{HuNu}$-positive cells were found in the ipsilateral hemisphere of cbMNC-, cbMSC-, and cmMSC-treated animals. $\mathrm{HuNu}$-positive cells were not present in the contralateral hemisphere of cell-transplanted animals, indicating the propensity of all three cell types to migrate through the ICA and to home sustainably to the region of infarction (Figure 4).

Relative to the PBS group, a marked decrease in Iba-1positive cells (activated macrophages/microglia) was observed in both ipsilateral cortex and more prominently in the striatum of cell-treated animals (Figure 5). Similar to reduction in Iba-1-positive cells, a trend of fewer CD68positive, activated microglia was seen in all three cellgroup animals compared to PBS-group animals (Figure 6).

Assessment of neuroprotective, antiinflammatory, and antioxidative effects of the three cell types in stroke rats We assessed the mRNA expression of nine rat-specific genes (BDNF, GPX-4, EGF, reelin, IL-2, IL-6, IL-10, IL-1beta, TNF-alpha) and three human-specific genes $(I L-2, I L-6$, and $I L-10)$ in the ipsilateral hemisphere of cell-treated, PBS, and sham-group animals. At 2 weeks after stroke, rat $B D N F$ mRNA expression was significantly higher in the ipsilateral hemisphere of the sham group compared with the PBS $(P<0.0001)$, cbMNC $(P<0.01)$, and $\mathrm{cb} / \mathrm{cmMSC}(P<0.001)$ groups. Compared with the cbMSC, cmMSC, and PBS groups, rat BDNF mRNA showed a trend of higher expression in the cbMNC group (Figure 7). At day 14 after stroke, a trend of enhanced expression of rat reelin and GPx-4 mRNA was detected in sham and cbMNC-treated animals compared with the PBS group. No significant difference was observed in rat EGF mRNA expression among the PBS, sham, and cell-treated groups. Relative to the PBS group, expression of rat $I L-2$ mRNA was low in the sham and cell groups, with a significant decrease in the cbMSC and cmMSC groups $(P<0.001)$. Rat $I L-6$ mRNA was significantly lower in the cbMSC and sham groups $(P<0.001)$ and was detected at high levels in the cmMSC and cbMNC groups (difference not significant).

The lowest expression of rat IL-1beta mRNA was detected in cbMSC-treated animals $(P<0.001)$, with no significant difference between the sham, PBS, cbMNC, and 
Table 1 Percentage expression of phenotypic cell markers in cbMSCs, cmMSCs, and cbMNCs

\begin{tabular}{|c|c|c|c|c|}
\hline Marker & cbMSC & cmMSC & cbMNC & Function of marker \\
\hline $\mathrm{CD7}$ & 0.407 & 5.4 & 62.51 & Marker for thymocytes and mature T cells \\
\hline CD4 & 5.88 & 68.0 & 26.77 & Marker for T-helper cells, regulatory T cells, monocytes \\
\hline CD25 & 91.2 & 71.3 & 71.8 & Part of IL-2 receptor present on activated T cells/B cells \\
\hline CD3 & 36.3 & 4.33 & 31.3 & T-cell coreceptor and marker for mature T cells \\
\hline CD8 & 0.123 & 0.277 & 21.1 & $\begin{array}{l}\text { Coreceptor for T-cell receptor and binds specifically to major } \\
\text { histocompatibility complex (MHC) I }\end{array}$ \\
\hline CD44 & 100 & 99.7 & 81.7 & $\begin{array}{l}\text { Marker for effector memory T cells, lymphocyte activation, receptor } \\
\text { for hyaluronic acid }\end{array}$ \\
\hline$H L A-A B C$ & 96.9 & 98.8 & 92.4 & MHC Class I \\
\hline CD90 & 73.5 & 99.8 & 36.5 & $\begin{array}{l}\text { Marker for mesenchymal stem cells, hematopoietic stem cells (HSCs), } \\
\text { and fibroblasts }\end{array}$ \\
\hline CD56 & 1.28 & 80.8 & 11.3 & $\begin{array}{l}\text { Neuronal cell-adhesion molecule, plays role in synaptic plasticity and } \\
\text { neurite outgrowth }\end{array}$ \\
\hline CD210 & 91.8 & 96.5 & 0.544 & IL-10 receptor on T cells/B cells, natural killer (NK) cells, and monocytes \\
\hline CD45 & 0.99 & 0.82 & 87.7 & Leukocyte common antigen \\
\hline CD14 & 0.404 & 20.3 & 12.4 & Monocyte differentiation antigen \\
\hline CD34 & 0.124 & 1.57 & 0.80 & Marker for primitive hematopoietic and endothelial stem cells \\
\hline CD133 & 0.11 & 0.899 & 0.897 & $\begin{array}{l}\text { Prominin-1, specific for hematopoietic stem cells, endothelial progenitors, } \\
\text { neuronal and glial stem cells }\end{array}$ \\
\hline CD117 & 99.5 & 92.9 & 2.2 & $\begin{array}{l}\text { Stem cell growth-factor receptor, expressed on HSCs, multipotent } \\
\text { progenitors, common myeloid progenitors }\end{array}$ \\
\hline CD73 & 100 & 99.5 & 5.75 & Lymphocyte differentiation marker \\
\hline CD123 & 91.8 & 48.8 & 1.81 & IL-3 receptor on pluripotent progenitors \\
\hline CD16 & 31.5 & 72 & 81.9 & Marker for NK cells, monocytes, and macrophages \\
\hline CD166 & 100 & 99.8 & 3.38 & Activated leukocyte cell-adhesion molecule \\
\hline Lin1 & 0.46 & 31.6 & 87.2 & Lineage cocktail $1(\mathrm{CD} 3,14,16,19,20,56)$ \\
\hline CD59 & 99.8 & 99.3 & 7.14 & $\begin{array}{l}\text { Complement regulatory protein, regulates complement-mediated cell } \\
\text { lysis by formation of membrane-attack complex }\end{array}$ \\
\hline CD106 & 16.21 & 23.0 & 3.54 & Vascular cell-adhesion molecule (VCAM)-1 \\
\hline CD184 & 100 & 75.6 & 64.4 & Chemokine (C-X-C motif) receptor-4 specific for stromal-derived factor-1 \\
\hline HLA-DR & 0.434 & 0.312 & 31.6 & MHC Class II \\
\hline CD19 & 6.89 & 0.399 & 9.27 & Marker for follicular dendritic cells and B cells \\
\hline CD33 & 1.26 & 0.313 & 27.3 & Marker for myeloid-lineage cells \\
\hline
\end{tabular}

Represents comparative percentage expression of various markers assessed with flow cytometry by using Becton Dickinson LSR II (Stanford Shared FACS facility).

cmMSC groups. No significant difference was detected in expression of rat TNF-alpha mRNA between groups, although cmMSCs showed a trend of higher TNF-alpha mRNA expression. No expression of rat $I L-10$ mRNA or human-origin cytokine mRNA ( $I L-2, I L-6, I L-10)$ could be detected in any of the study groups.

\section{cbMNCs and cbMSCs showed no adverse effects and decreased mortality after stroke}

No cell-related adverse events were observed in cbMNCand cbMSC-treated animals after transplantation. Of 23 animals treated with $5 \times 10^{6} \mathrm{cmMSCs}$, one animal developed severe inflammation in the ipsilateral eye within 24 hours of transplantation (see Additional file 4). In contrast, the incidence of severe inflammation of the ipsilateral eye in animals transplanted with $10 \times 10^{6} \mathrm{cmMSCs}$ was significantly higher (three of six). Of these four total animals with severe eye inflammation, all three of the animals transplanted with $10 \times 10^{6}$ cells died within 24 hours; however, the animal transplanted with $5 \times 10^{6} \mathrm{cmMSCs}$ survived to day 14 (Table 2). A trend of decreased overall mortality after stroke was seen in the cbMNC (8\%) and cbMSC (11\%) groups relative to the PBS (22\%) group. The overall mortality rate was highest in the cmMSC (26\%) group, although the difference in mortality of all three cell-group animals and the PBS group was not significant (Table 2). No animals died within 24 hours of cbMNC $\left(10 \times 10^{6}\right)$, $\operatorname{cbMSC}\left(5 \times 10^{6}\right)$, or cmMSC $\left(5 \times 10^{6}\right)$ 


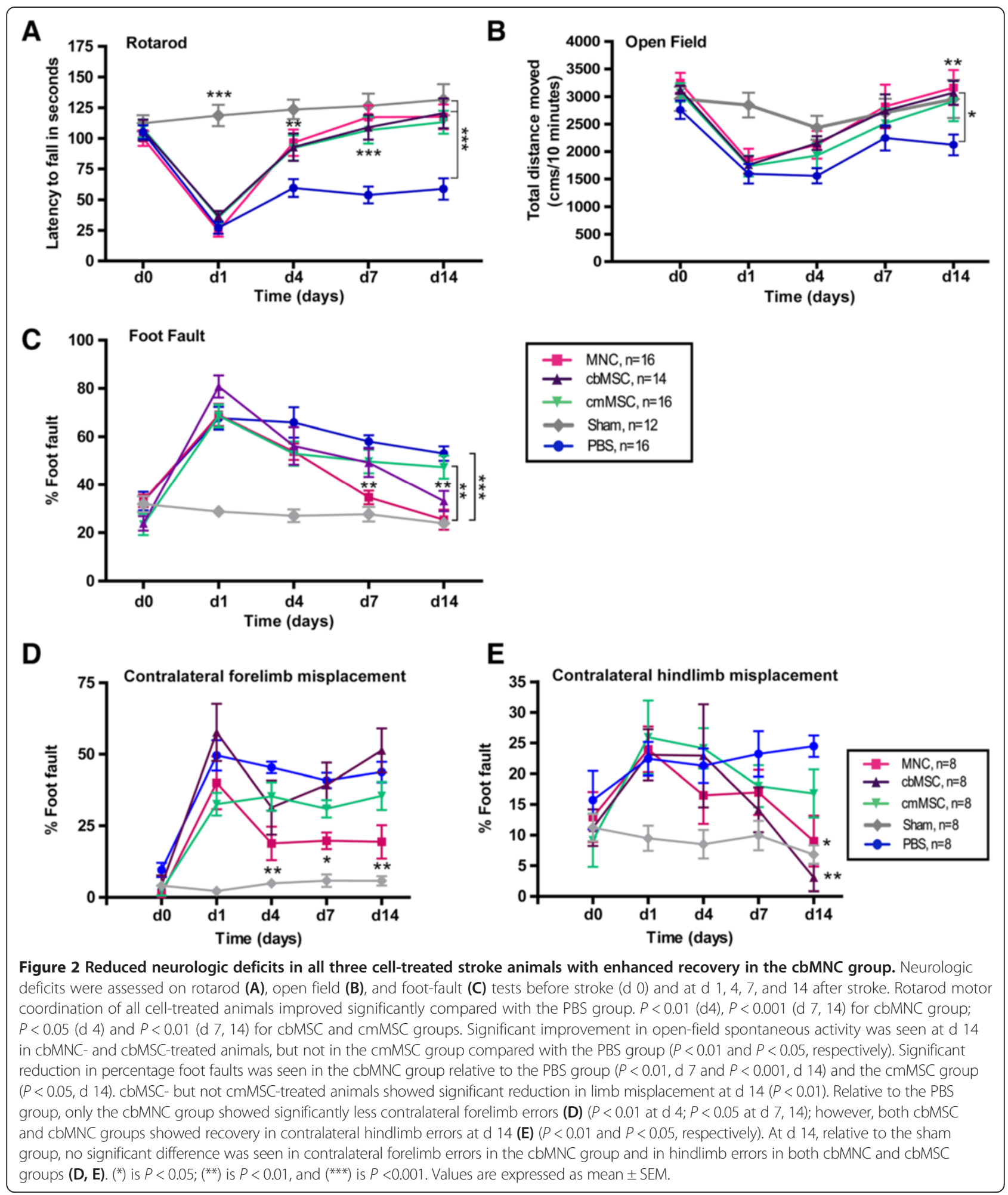

transplantation compared with one animal from the PBS group. In contrast, all six animals transplanted with $10 \times$ $10^{6} \mathrm{cmMSCs}$ died within 24 hours of transplantation (Table 2).

\section{Discussion}

HUC blood is a promising source of cells for the treatment of stroke, either by using a heterogeneous mix of unprocessed cells or by preselecting a specific cell population 


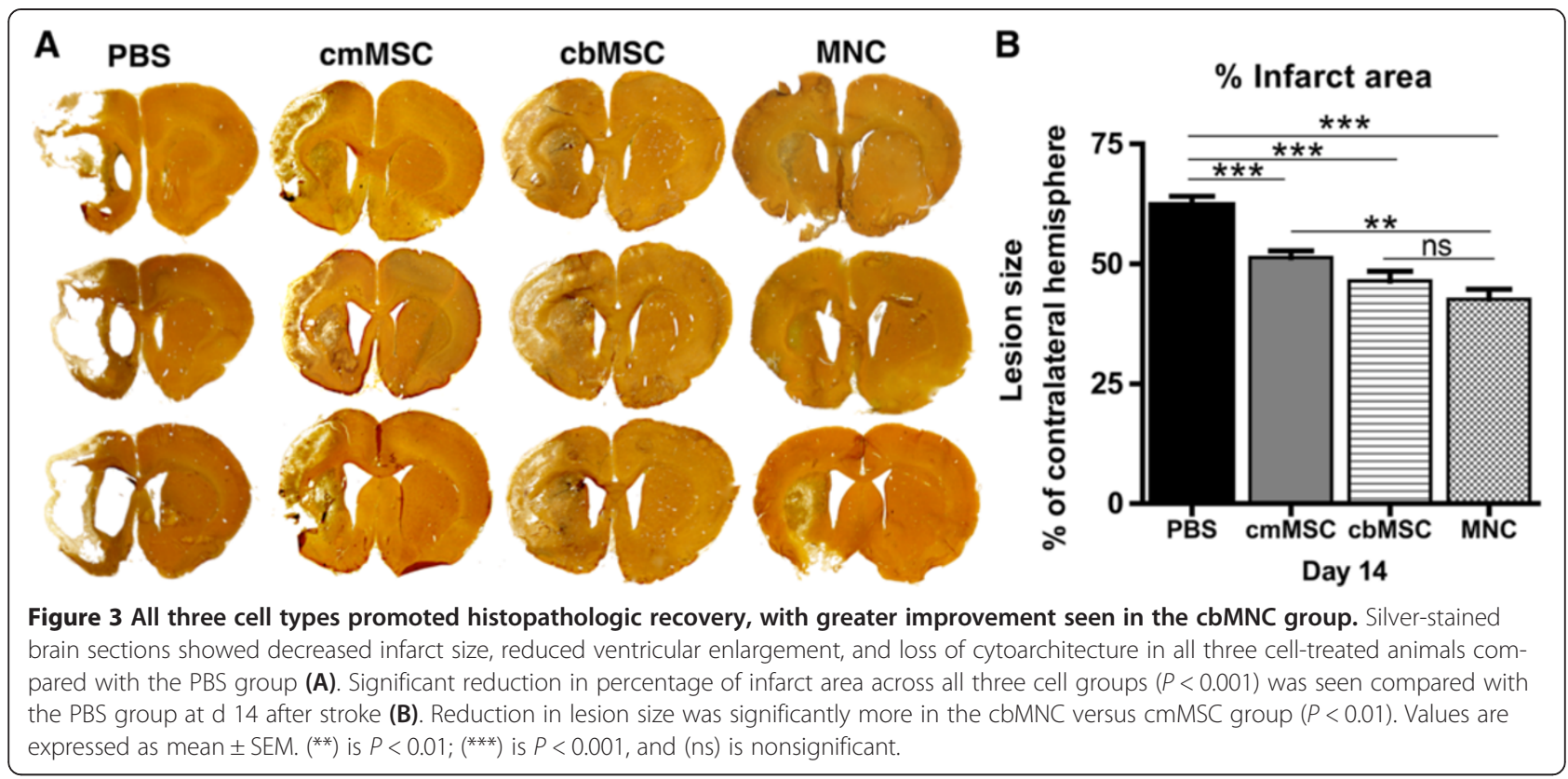

from it [11]. Although these two therapeutic avenues have been tested in various preclinical stroke studies with beneficial effects, it is not yet known whether one is more effective than the other. Thus, we compared the cbMNC population, which is a heterogeneous mix of hematopoietic, mesenchymal, and endothelial stem/progenitor cells, along with immature immunological cells [12], with MSCs derived from cbMNCs and cord matrix.

Although, in principle, transplantation of a xenogenic graft might induce a local immune response in the host, preclinical and clinical reports have raised the possibility of using HUC-derived cells without immunosuppression $[12,17]$. Reports have also suggested that immunosuppression is neuroprotective $[73,74]$. Therefore, to assess the safety and unbiased efficacy of these cells, we omitted immunosuppression in our study.

Cord-blood-derived cells and other stem cells can be chemotactically attracted to the site of injury [17]. It is thus reasonable to opt for systemic rather than intracerebral delivery to avoid tissue damage at the injection site [75]. Further, selection of intraarterial over intravenous injection was based on study results that showed that more cells reach the MCA territory when transplanted intraarterially [76,77] and another study that showed approximately $96 \%$ of cells transplanted intravenously were trapped in the lungs and did not reach the arterial circulation in a traumatic brain injury model [78].

As transplanted cell survival in the host brain of immunocompetent rats was one of our outcome measures, we opted to transplant these cells intraarterially.

A dose-response study of cord-blood-derived cells suggested that delivery of $10^{6}$ cells was sufficient to result in significant functional recovery and that doses of $>10^{6}$ cells resulted in functional as well as histopathologic recovery [24]. We thus opted for a dose of $10^{7}$ cells to assess the comparative effects of transplanted cbMNCs and $\mathrm{cb} / \mathrm{cmMSCs}$. However, we decreased the dose to $5 \times 10^{6}$ for $\mathrm{cb} / \mathrm{cmMSCs}$, as intraarterial injection of $10^{7} \mathrm{cmMSCs}$ resulted in severe inflammation of the ipsilateral eye, followed by acute mortality in our study animals. Thus, $5 \times$ $10^{6}$ cells was the maximum number of $\mathrm{cb} / \mathrm{cmMSCs}$ we could safely transplant (Table 2). MSCs have a tendency to aggregate into multicellular globules [79], thus at higher concentrations, they can result in vascular embolization.

Our data suggest that cbMNCs are more effective than $\mathrm{cb} / \mathrm{cmMSCs}$ in promoting functional recovery and reducing infarct. Although we would have preferred to inject the same doses of cbMNCs and cb/cmMSCs, we think it is unlikely that a twofold difference in transplanted-cell numbers could account for increased beneficial effects of cbMNCs. Furthermore, cbMSCs comprise a very small subset $(0.001 \%$ to $0.000001 \%)$ of cbMNCs [80]. Therefore, it is reasonable to assume that an enriched preselected population of MSCs would have been equally or more effective at a lesser dose, if they were the critical cbMNC subpopulation that mediates recovery. Our flow-cytometry data showed that the cultured fraction of cbMNCs was enriched in $\mathrm{CD}_{7}{ }^{+} \mathrm{CD} 166^{+} \mathrm{CD} 90^{+} \mathrm{CD} 45^{-} \mathrm{HLA}^{-} \mathrm{DR}^{-}$ cells (cbMSCs). These cultured cbMSCs showed an approximately 20-fold increase in expression of MSC markers, resulting in a very effective enrichment of cbMSCs from the cbMNCs. Thus, $5 \times 10^{6}$ transplanted cbMSCs contained 10 -fold more cbMSCs than in $10 \times 10^{6}$ cbMNCs. The enhanced recovery in the cbMNC group compared with the 


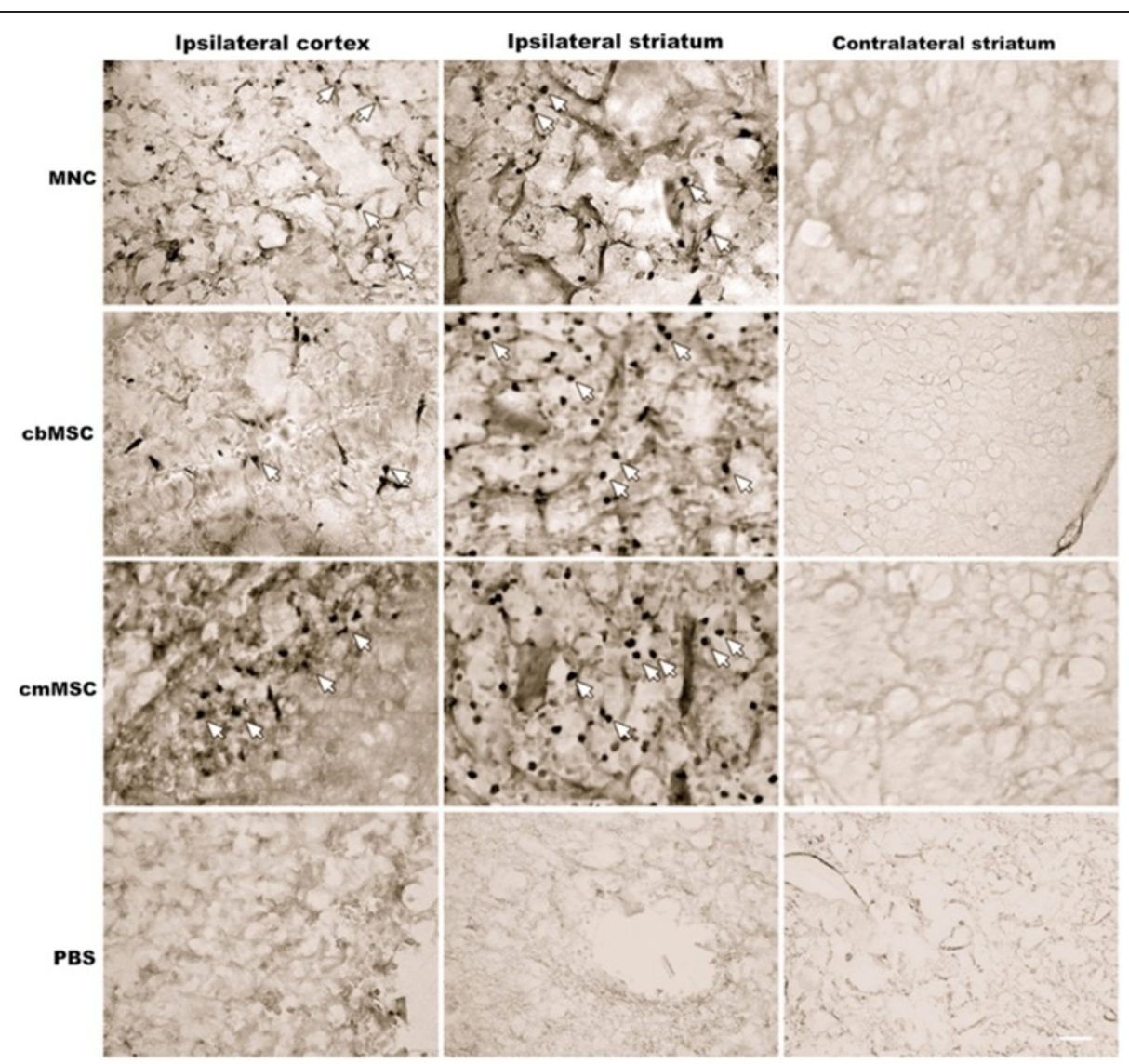

Figure 4 Distribution of transplanted cells in the ischemic hemisphere relative to the contralateral hemisphere. All three cell types migrated from the ICA to the ischemic hemisphere and were localized predominantly in the cortex and striatum of the infarct boundary zone (IBZ). Arrows represent MAB1281-positive cells. No MAB1281 (HuNu)-positive cells were found in the contralateral hemisphere of any of the three cell groups. Similarly, no MAB1281 staining was seen in the ipsilateral or contralateral hemisphere of PBS rats. Scale bar $=10 \mu \mathrm{m}$.

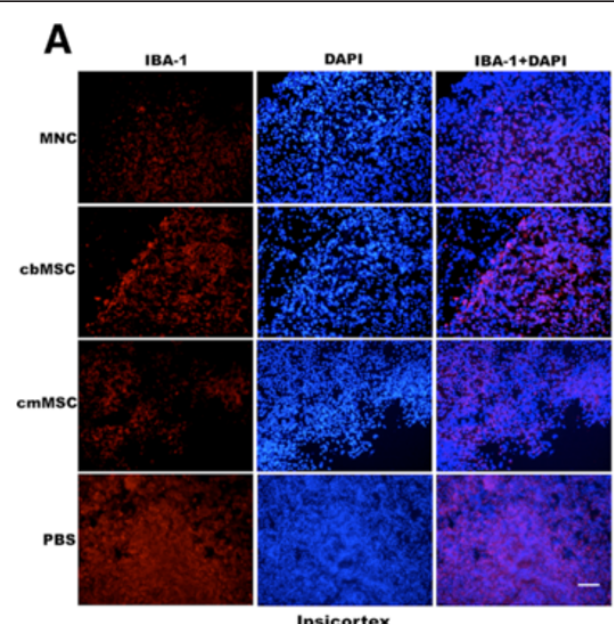

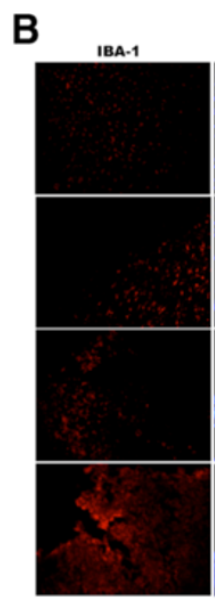

Ipsicortex

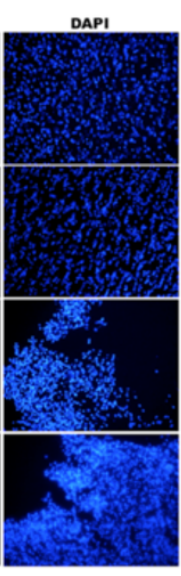

Ipsistriatum

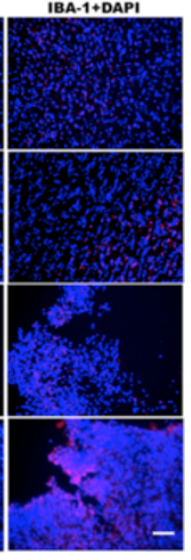

Figure 5 Photomicrographs showing expression of ionized calcium-binding adapter molecule-1 (Iba-1) in ipsilateral hemisphere of cell-transplanted and PBS-group animals. A marked decrease in activated macrophage/microglial lba-1-positive cells was seen in all three cell-group animals compared with the PBS group. The Iba-1-positive cells seen in cell-group animals had both ramified and amoeboidal morphology compared with more-compact amoeboidal morphology seen in the PBS group. Decrease in expression of Iba-1 was more prominent in ipsi-striatum (B) than in ipsi-cortex (A). Scale bar $=100 \mu \mathrm{m}$. 


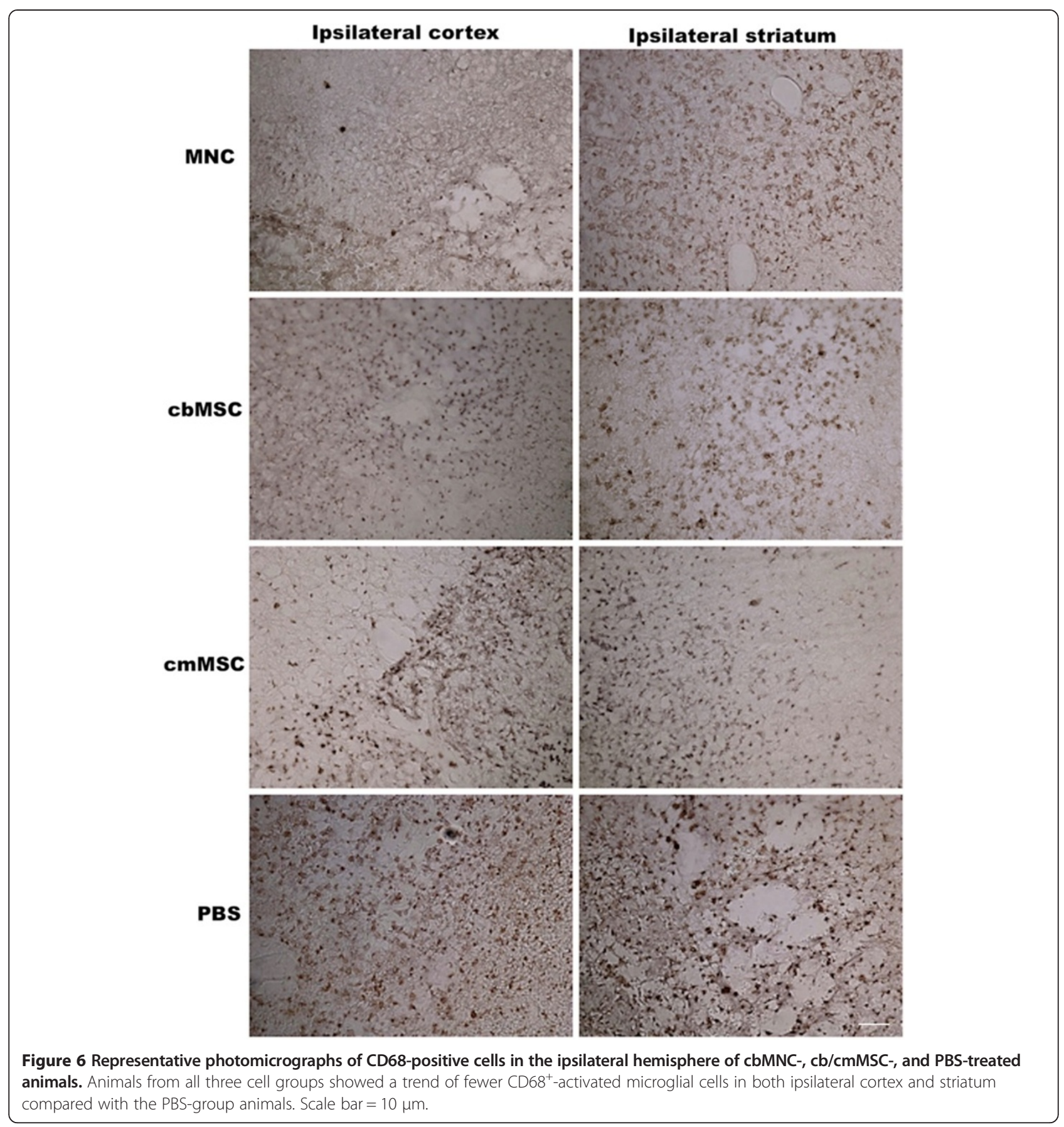

enriched $\mathrm{cb} / \mathrm{cmMSC}$ groups could be due to additional cell fractions in the cbMNCs that might secrete factors important for recovery. Thus, the as-yet-uncharacterized functional properties of cbMNC subpopulations and their possible interactions, rather than total cell numbers, could be responsible for the beneficial effects of transplanted cbMNCs. The enhanced recovery with cbMNCs thus may be partially attributable to the integrative effects of various stem/progenitor cell fractions present in this cell population.
A recent study [81] compared the effects of cbMNCs with CD34-enriched and CD34-depleted cbMNC fractions in spontaneously hypertensive stroke rats. The study reported superior effects of cbMNCs relative to the $\mathrm{CD} 34^{+}$ and CD34- fractions, suggesting the possibility that the combined effect of other cell fractions was necessary for the overall neuroprotective effect.

Although rats in both the cbMNC and cbMSC groups showed improvement in sensory motor functions, only 


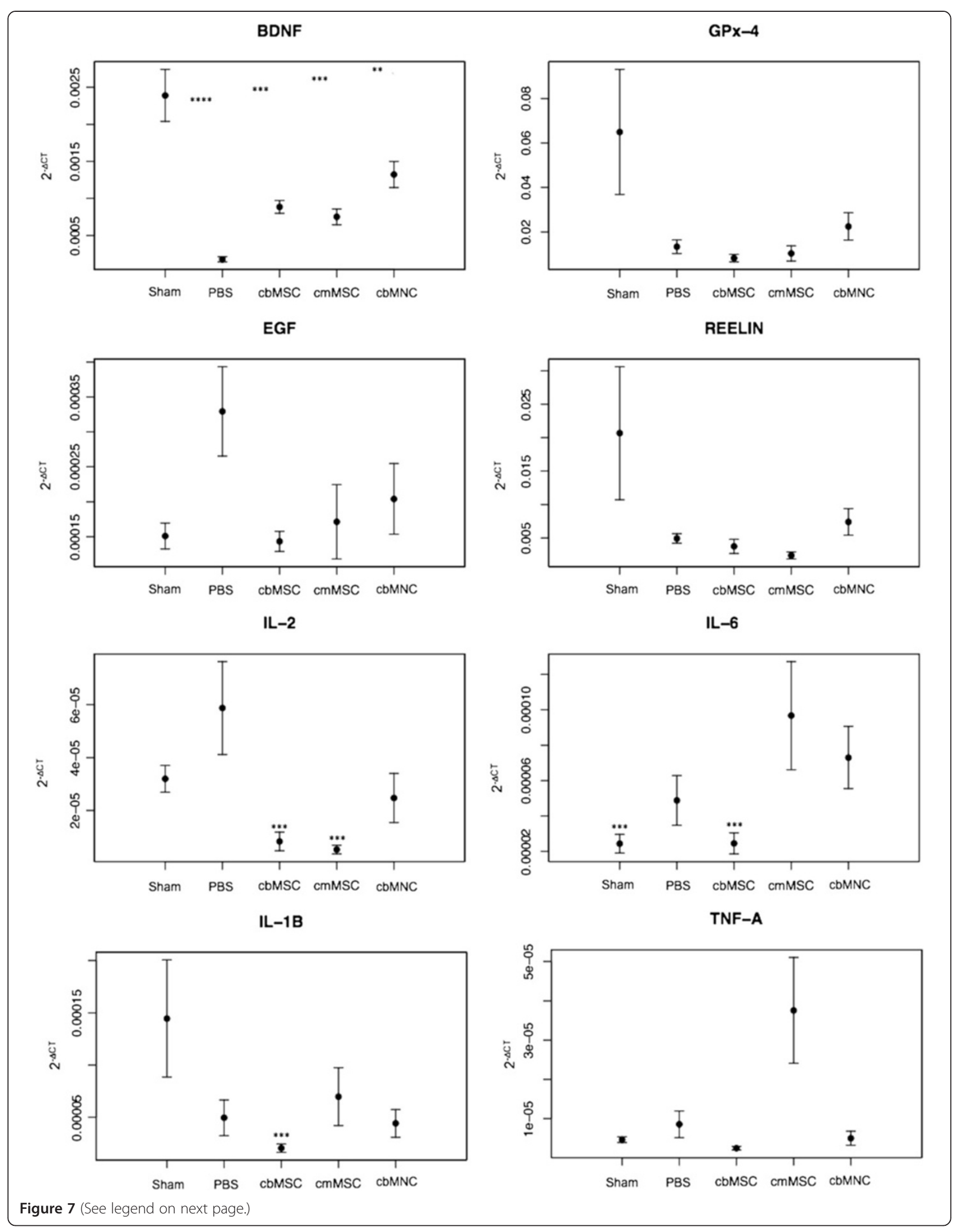


(See figure on previous page.)

Figure 7 Quantification of mRNA expression of rat-specific BDNF, GPX-4, EGF, reelin, IL-2, IL-6, IL-1beta, and TNF-alpha in the ipsilateral hemisphere. At 2 weeks after stroke, rat BDNF mRNA expression in sham rats was significantly more compared with PBS $(P<0.0001)$, cbMNC $(P<0.01)$, and cb/cmMSC $(P<0.001)$ groups. Rat BDNF mRNA expression was relatively more in the cbMNC group compared with the cb/cmMSC and PBS groups. No significant difference was seen in expression of rat EGF, reelin, GPX-4, and TNF-alpha across the cell-treated, sham, and PBS groups, although there was an enhanced expression of GPX-4 and reelin mRNA in CbMNC and sham animals. Significantly decreased IL-2 mRNA expression was seen in the $\mathrm{cb} / \mathrm{cmMSC}$ groups $(P<0.001)$. Compared with the PBS group, expression of $I L-6 \mathrm{mRNA}$ was significantly less in cbMSC-and sham-group animals $(P<0.001)$. Significantly decreased expression of rat $I L-1$ beta mRNA was seen only in the cbMSC group $(P<0.001)$. Values are expressed as mean $\pm \mathrm{SEM},\left({ }^{*}\right)$ is $P<0.05 ;\left(^{(*)}\right.$ is $P<0.01 ;\left(^{* * *}\right)$ is $P<0.001$; and $\left({ }^{* * *}\right)$ is $P<0.0001$.

cbMNC-treated rats showed early (within 7 days) recovery in the grid-walk test. This was likely attributable to the significant improvement seen in both contralateral forelimb and hindlimb deficits in this group. Infarct size was also most reduced in the cbMNC group and was significantly smaller than that in the cmMSC group. Although cbMNCs have been shown to produce various growth factors, such as $V E G F$ and $B D N F$ [82], it is probably their ability to induce enhanced expression of endogenous $B D N F$ [29] that partially resulted in enhanced recovery in this group. $B D N F$ is known to mediate proliferation of existing vascular endothelial cells $[83,84]$, survival and migration of neuronal cells, along with modulation of their synaptic functions [51,52], and to exert neuroprotective effects via downregulation of neuronal NOS (nNOS) activity [85]. Intravenous infusion of $B D N F$ has been shown to reduce infarct volume as early as 5 hours after stroke [47].

Further, the increased mRNA expression of rat-specific $B D N F$ seen in sham versus PBS animals implies a reduction in the BDNF endogenous levels after stroke. Thus, cbMNCs and, to a lesser extent, $\mathrm{cb} / \mathrm{cmMSCs}$, possibly restore the stroke-induced depletion of endogenous $B D N F$ [86]. In addition, the trend of increased expression of rat GPx-4 mRNA in cbMNC-treated animals indicates a possible role of MNCs in abating the effects of oxidative stress on GPx-4 levels. The restored GPx- 4 might in turn downregulate lipid peroxidation, resulting in decreased neuronal cell death and enhanced overall recovery.
Similar to earlier reports [16,24], transplanted cbMNCs, cbMSCs, and cmMSCs were seen predominantly in the ischemic hemisphere where homing is likely facilitated by chemokine receptor type-4 (CXCR4)-CXCL12 or CD117-stem cell factor (SCF) interactions. Upregulation of CXCL12/stromal-derived factor 1(SDF-1) has been reported in the ischemic penumbra $[87,88]$, and its interaction with (CXCR-4)/CD184 (expressed by all three cell populations used in our study) is known to promote migration of cbMNCs [89]. Also, enhanced expression of SCF has been reported in neurons within the injured hemisphere [90] and might have played a role in directed migration of transplanted $\mathrm{cb} / \mathrm{cmMSCs}$, both of which had significant expression of the SCF receptor CD117, as shown in our comparative flowcytometry experiment.

We observed decreased numbers of CD68- and amoeboidal Iba-1-positive cells in our cell-treated versus PBS animals, indicating a decrease in activated microglia. These resident immune cells are known to acquire a phagocytic phenotype after stroke that disrupts the blood-brain barrier and increases inflammation through release of proinflammatory cytokines, free radicals, and recruitment of leukocytes from the circulatory system [91,92]. Thus, a decrease in activated microglial cells in the injured brain after HUC-derived cell treatment represents an immunomodulatory effect that could reduce neuroinflammation and increase recovery. Although how HUC-derived cells

Table 2 Adverse effects and mortality after cell transplantation

\begin{tabular}{|c|c|c|c|c|c|}
\hline \multirow[t]{2}{*}{ Cell type } & \multirow[t]{2}{*}{ Cell dose } & \multicolumn{2}{|l|}{ Cell-related adverse effects after transplantation } & \multicolumn{2}{|c|}{$\begin{array}{l}\% \text { Mortality (number of deaths/total number) } \\
\text { after transplantation }\end{array}$} \\
\hline & & $<24$ hours & $>24$ hours & $<24$ hours & $>24$ hours \\
\hline cbMNCs & $10 \times 10^{6}$ & None & None & 0 (Nonsignificant) & $8 \%(2 / 24)$ (Nonsignificant) \\
\hline \multirow[t]{2}{*}{ cmMSCs } & $10 \times 10^{6}$ & 3/6 animals developed severe inflammation in ipsilateral eye & None & $100 \%(6 / 6) * P<0.0001$ & - \\
\hline & $5 \times 10^{6}$ & 1/23 animals developed severe inflammation in ipsilateral eye & None & 0 (Nonignificant) & $26 \%(6 / 23)$ (Nonsignificant) \\
\hline cbMSCs & $5 \times 10^{6}$ & None & None & 0 (Nonsignificant) & $11 \%(2 / 18)$ (Nonsignificant) \\
\hline
\end{tabular}

Adverse effects and mortality after cell transplantation. The table shows cell-related adverse effects within 24 hours and $>24$ hours of cell transplantation. Both cbMNC- and cbMSC-group animals had no adverse effects after cell transplantation. One animal transplanted with $5 \times 10^{6} \mathrm{cmMSCs}$ and three animals transplanted with $10 \times 10^{6} \mathrm{cmMSCs}$ had severe inflammation of the ipsilateral eye within 24 hours of transplantation. The mortality rate was calculated, for two time points, within 24 hours and $>24$ hours, as a percentage of animals that died to the total animals in each group. A decreasing trend in mortality was seen in the cbMNC and cbMSC groups, but not in the cmMSC group compared with the PBS group. The mortality rate within 24 hours of transplantation in animals transplanted with $10 \times 10^{6} \mathrm{cmMSC}$ was significantly higher compared with the PBS group animals $(P<0.0001)$. ${ }^{*} P$ value relative to the PBS group calculated with the Fisher Exact test. Significance was ascertained at $P<0.05$. 
suppress activated microglia is unknown, a recent study implicates the role of $\mathrm{CD}_{11 \mathrm{~b}^{+}}$and $\mathrm{CD} 19^{+}$cbMNCs in reducing microglial survival and $\mathrm{CD}^{+}$in sustaining microglia in vitro after hypoxic conditions [91]. In our study, cbMNCs were $\mathrm{CD} 19^{+} \mathrm{CD} 4^{+}$, cmMSCs were $\mathrm{CD} 19^{-}$, but had enriched $\mathrm{CD}_{4}^{+}$expression, whereas cbMSCs had negligible expression of both CD19 and CD4. Thus, markedly reduced activated microglial cells in each of these three cell groups indicates that additional factors could be involved in mediating microglial suppression as well as the possibility that $\mathrm{CD} 19^{+}$cells override the protective effects of $\mathrm{CD} 4^{+}$cells.

In stroke, various pro-inflammatory cytokines are secreted from infiltrated leukocytes and macrophages through activation of resident microglia. The insignificant differences in $I L-6, I L-\beta$, and TNF-alpha mRNA expression within the cbMNCs and cmMSCs groups compared with control animals may be due to timedependent expression patterns. These cytokines have been shown to peak in expression in the ischemic hemisphere at day 7 after stroke, which was decreased by day 14 [93]. The significant decrease in $I L-2, I L-6$, and $I L-$ 1beta mRNA in the cbMSC group could indicate a mechanistic shift of action of these cells from their parental cbMNC population. Whereas suppression of proinflammatory factors might mediate the recovery observed in cbMSC-treated animals, in the cbMNC group, recovery is more likely associated with the release of growth factors and the ability to attenuate oxidative stress. The negligible antiinflammatory cytokine $I L-10$ mRNA seen in our study is similar to that of previous reports [93] in which no expression was seen at day 14 after stroke.

The absence of any human cytokine expression in the ipsilateral hemisphere of the transplanted animals is possibly due to the moderate number of surviving human cells, low levels of cytokine secretion by the transplanted cells, or reduced overall inflammation by day 14 after stroke. Future studies assessing the treatment and timedependent profile of these cytokines will enhance our understanding of inflammation and the effects of umbilical cord cell subtypes on the same. At 2 weeks after stroke, insignificant differences in the expression of reelin and EGF mRNA between the PBS, sham, and cell groups could indicate that reelin-mediated migration of progenitors and $E G F$-mediated recovery after stroke is time dependent.

Cell survival in immunocompetent stroke rat brains and the absence of adverse events in cbMNCs and cbMSCs might be due to their immunomodulatory function in addition to the presence of phenotypically and functionally immature T-lymphocytes [94]. Cord blood has a higher percentage of homogeneous regulatory $\mathrm{T}$-lymphocytes (Tregs) compared with heterogeneous Tregs present in peripheral blood and a smaller percentage in bone marrow [95]. Tregs are known to dampen the immune response
[96] and have been shown to exert potent antiinflammatory neuroprotective effects after stroke [97]. HUC blood Tregs have also been shown clinically to prevent allogeneic acute graft-versus-host disease (GVHD) [98]. It is therefore important to understand the role of this subpopulation in mediating the survival of transplanted HUCderived cells without adverse effects and whether these cells play a role in poststroke recovery. Although many studies with Treg-depleted donor allografts have shown enhanced GVHD [99-101], it is worth exploring whether Treg-depleted cord-blood-derived cells home and exert similar neuroprotective effects in stroke, as seen in this study. Further, it would be interesting to determine whether cord-blood and matrix cells have phenotypically and functionally similar Treg populations.

Last, although both cbMSCs and cmMSCs showed similar expression of MSC-specific markers, they differed in their expression of Lin1, CD56, CD4, and CD14, which could account for the differences in functional and histopathologic recovery seen with these cells. It would be interesting to determine whether these differences are preserved with cbMSCs and cmMSCs isolated from the same donor. Further, because of phenotypical and functional heterogeneity within MSC preparations and variations between MSC donors, it would be informative to include multiple MSC preparations from multiple donors in MSC studies [102,103].

We analyzed cbMSCs isolated from a single donor, which is a limitation of our study. Future studies comparing cbMSCs isolated from multiple donors would therefore provide valuable information on donor-dependent and/or MSC-subpopulation variations in the context of cbMSC transplantation after stroke.

\section{Conclusions}

Our study data show that cbMNCs, cbMSCs, and cmMSCs are effective in ameliorating the effects of stroke. However, cbMSCs, an enriched cell population of cbMNCs, or cmMSCs, did not show superior performance in stroke rats compared with the heterogeneous cbMNCs. cbMNCs are widely accessible and more easily prepared compared with processed and ex vivo expanded MSCs. Further, the sustainable homing of cbMNCs similar to $\mathrm{cb} / \mathrm{cmMSCs}$ and the absence of severe cell-related adverse effects, as seen with cmMSCs, suggests cbMNCs to be a promising cell therapy for stroke.

\section{Additional files}

Additional file 1: Description of Data. List of antibodies used in

multicolor flow cytometry. Twenty-seven phenotypic cell markers were used for comparative immunophenotypic characterization of cbMSCs, cmMSCs, and cbMNCs. Antibodies for 27 markers were divided into six 
FACS tubes according to their conjugated fluorochromes and their emission range.

Additional file 2: Description of Data. Representative flow-cytometry dot plots of cbMSCs, cmMSCs, and cbMNCs. The plots illustrate expression of phenotypic cell markers CD59, CD184, CD106, CD90, CD210, CD73, CD56, CD44, CD117, CD123, CD166, HLA-ABC, HLA-DR. In each plot, percentage of cells positive for a given marker is shown on right, and percentage of cells negative for the same marker is shown on the left. Gates were set according to the unstained controls and compensation was done by single-color-stained BD-CompBeads.

Additional file 3: Description of Data. Representative flow-cytometry dot plots of cbMSCs, cmMSCs, and cbMNCs. The plots illustrate expression of phenotypic cell markers CD3, CD4, CD8, CD7, CD14, CD25, CD14, CD45, CD34, CD133, CD33, CD19, and CD106 (B) in all three cell groups (cbMSCs, cmMSCs, and cbMNCs). In each plot, percentage of cells positive for a given marker is shown on the right, and percentage of cells negative for the same marker is shown on the left. Gates were set according to the unstained controls, and compensation was done by single-color-stained BD-CompBeads.

Additional file 4: Description of Data. Photographs of two stroke rats taken 72 hours after $\mathrm{cmMSC}$ transplantation. One stroke rat from cmMSC group had severe inflammation in ipsilateral eye post cell $\left(5 \times 10^{6}\right)$ transplantation, which persisted until 14 days (A). The eye can be well demarcated from normal ipsilateral eye of another $\mathrm{cmMSC}$-transplanted animal with no adverse effect (B). Similar inflammation of the ipsilateral eye was also seen in three animals transplanted with $10 \times 10^{6} \mathrm{cmMSCs}$, all of which died within 24 hours of transplantation.

\section{Abbreviations}

BDNF: Brain-derived neurotrophic factor; cbMSCs: cord blood mesenchymal stromal cells; CCA: common carotid artery; CmMSCs: cord matrix MSCs; CXCR-4: chemokine receptor type; ECA: external carotid artery;

FACS: fluorescence-activated cell sorting; GAPDH: glyceraldehyde-3-phosphate dehydrogenase; GPx-4: glutathione peroxidase-4; HUC: human umbilical cord; HUCB: human umbilical cord blood; HuNu: human nuclei; Iba-1: ionizedcalcium-binding adapter molecule; IBZ: infarct boundary zone; ICA: interna carotid artery; MCAo: middle cerebral artery occlusion; MNCs: cord blood mononuclear cells; SCF: stem cell factor; SDF-1: stromal-derived factor-1; VSELs: very small embryonic-like stem cells.

\section{Competing interests}

The authors have no competing interests to declare.

\section{Authors' contributions}

NK conceived the study, designed and executed experiments, collected assembled, analyzed and interpreted data, and wrote and edited the manuscript. NCM contributed to GPCR experiments, analysis of data, and revision of the manuscript. KP contributed to analysis and interpretation of data and was involved in manuscript writing and editing. RS participated in analysis and interpretation of data, and contributed in writing and editing of the manuscript. GKS was involved in experimental design, analysis and interpretation of data, and writing and editing of the manuscript. All authors have read and approved the final manuscript.

\section{Acknowledgements}

We thank Mary Norton, MD, for provision of patients for cord blood collection; Shilpa P. Chetty, MD, for acquiring patient consent and collecting cord-blood samples; Robert Tibshirani, PhD, for statistical analysis of qPCR data; Guohua Sun, MD, for technical inputs; David Kunis, for laboratory management; Cindy H. Samos, for manuscript editing; and the United States-India Educational Foundation; Fulbright Commission and Institute of International Education, USA.

This work was carried out under Fulbright-Nehru Doctoral and Professional Research Fellowship (IIE Grantee ID:15101860) (NK) and was supported in part by NIH NINDS grant R01 NS058784, Russell and Elizabeth Siegelman, John and Dodie Rosekrans, Bernard Lacroute, Ronni Lacroute, the William Randolph Hearst Foundation, and the Edward G. Hills Fund (GKS).

\section{Author details}

'Department of Neurosurgery, R281, Stanford School of Medicine, Stanford University, Stanford, CA 94305-5487, USA. ${ }^{2}$ Stanford Stroke Center, Stanford University School of Medicine, Stanford University, Stanford, CA 94305, USA. ${ }^{3}$ Department of Neurology, All India Institute of medical Sciences, New Delhi 110029, India.

Received: 1 March 2013 Revised: 21 October 2013 Accepted: 20 March 2014 Published: 1 April 2014

\section{References}

1. Fruchtman SM, Hurlet A, Dracker R, Isola L, Goldman B, Schneider BL, Emre S: The successful treatment of severe aplastic anemia with autologous cord blood transplantation. Biol Blood Marrow Transplant 2004, 10:741-742.

2. Gluckman E, Broxmeyer HA, Auerbach AD, Friedman HS, Douglas GW, Devergie A, Esperou H, Thierry D, Socie G, Lehn P, Cooper S, English D, Kurtzberg J, Bard J, Boyse E: Hematopoietic reconstitution in a patient with Fanconi's anemia by means of umbilical-cord blood from an HLA-identical sibling. N Engl J Med 1989, 321:1174-1178.

3. Locatelli F, Rocha V, Reed W, Bernaudin F, Ertem M, Grafakos S, Brichard B, Li X, Nagler A, Giorgiani G, Haut PR, Brochstein JA, Nugent DJ, Blatt J, Woodard P, Kurtzberg J, Rubin CM, Miniero R, Lutz P, Raja T, Roberts I, Will AM, Yaniv I, Vermylen C, Tannoia N, Garnier F, lonescu I, Walters MC, Lubin $\mathrm{BH}$, Gluckman $\mathrm{E}$, et al: Related umbilical cord blood transplantation in patients with thalassemia and sickle cell disease. Blood 2003, 101:2137-2143.

4. Rocha V, Cornish J, Sievers EL, Filipovich A, Locatelli F, Peters C, Remberger M, Michel G, Arcese W, Dallorso S, Tiedemann K, Busca A, Chan KW, Kato S, Ortega J, Vowels M, Zander A, Souillet G, Oakill A, Woolfrey A, Pay AL, Green A, Garnier F, lonescu I, Wernet P, Sirchia G, Rubinstein P, Chevret S, Gluckman E: Comparison of outcomes of unrelated bone marrow and umbilical cord blood transplants in children with acute leukemia. Blood 2001, 97:2962-2971.

5. Hows JM, Marsh JC, Bradley BA, Luft T, Coutinho L, Testa NG, Dexter TM: Human cord blood: a source of transplantable stem cells? Bone Marrow Transplant 1992, 9:105-108.

6. Lewis ID, Verfaillie CM: Multi-lineage expansion potential of primitive hematopoietic progenitors: superiority of umbilical cord blood compared to mobilized peripheral blood. Exp Hemato/ 2000, 28:1087-1095.

7. Ringden $\mathrm{O}$, Okas M, Uhlin M, Uzunel M, Remberger M, Mattsson J: Unrelated cord blood and mismatched unrelated volunteer donor transplants, two alternatives in patients who lack an HLA-identical donor. Bone Marrow Transplant 2008, 42:643-648.

8. Rocha V, Labopin M, Sanz G, Arcese W, Schwerdtfeger R, Bosi A, Jacobsen N, Ruutu T, de Lima M, Finke J, Frassoni F, Gluckman E, Acute Leukemia Working Party of European Blood and Marrow Transplant Group; EurocordNetcord Registry: Transplants of umbilical-cord blood or bone marrow from unrelated donors in adults with acute leukemia. N Engl J Med 2004 351:2276-2285.

9. Harris DT: Non-haematological uses of cord blood stem cells. Br J Haematol 2009, 147:177-184.

10. McGuckin C, Forraz N, Baradez MO, Basford C, Dickinson AM, Navran S, Hartgerink JD: Embryonic-like stem cells from umbilical cord blood and potential for neural modeling. Acta Neurobiol Exp (Wars) 2006, 66:321-329.

11. Rosenkranz K, Meier C: Umbilical cord blood cell transplantation after brain ischemia: from recovery of function to cellular mechanisms. Ann Anat 2011, 193:371-379.

12. Yang WZ, Zhang $Y$, Wu F, Min WP, Minev B, Zhang M, Luo XL, Ramos F, Ichim TE, Riordan NH, Hu X: Safety evaluation of allogeneic umbilical cord blood mononuclear cell therapy for degenerative conditions. J Trans/ Med 2010, 8:75.

13. Yang WZ, Zhang Y, Wu F, Zhang M, Cho SC, Li CZ, Li SH, Shu GJ, Sheng YX, Zhao N, Tang Y, Jiang S, Jiang S, Gandjian M, Ichim TE, Hu X: Human umbilical cord blood-derived mononuclear cell transplantation: case series of 30 subjects with hereditary ataxia. J Trans/ Med 2011, 9:65.

14. Ramirez F, Steenblock DA, Payne AG, Darnall L: Umbilical cord stem cell therapy for cerebral palsy. Med Hypotheses Res 2006, 3:679-686.

15. Kang KS, Kim SW, Oh YH, Yu JW, Kim KY, Park HK, Song CH, Han H: A 37-year-old spinal cord-injured female patient, transplanted of multipotent stem cells from human UC blood, with improved sensory 
perception and mobility, both functionally and morphologically: a case study. Cytotherapy 2005, 7:368-373.

16. Boltze J, Kowalski I, Geiger K, Reich D, Gunther A, Buhrle C, Egger D, Kamprad M, Emmrich F: Experimental treatment of stroke in spontaneously hypertensive rats by CD34+ and CD34- cord blood cells. Geriatr Med Sci 2005, 3:1-15.

17. Chen J, Sanberg PR, Li Y, Wang L, Lu M, Willing AE, Sanchez-Ramos J, Chopp M: Intravenous administration of human umbilical cord blood reduces behavioral deficits after stroke in rats. Stroke 2001, 32:2682-2688

18. Koh SH, Kim KS, Choi MR, Jung KH, Park KS, Chai YG, Roh W, Hwang SJ, Ko HJ Huh YM, Kim HT, Kim SH: Implantation of human umbilical cord-derived mesenchymal stem cells as a neuroprotective therapy for ischemic stroke in rats. Brain Res 2008, 1229:233-248.

19. Liao W, Xie J, Zhong J, Liu Y, Du L, Zhou B, Xu J, Liu P, Yang S, Wang J, Han Z, Han ZC: Therapeutic effect of human umbilical cord multipotent mesenchymal stromal cells in a rat model of stroke. Transplantation 2009, 87:350-359.

20. Lim JY, Jeong CH, Jun JA, Kim SM, Ryu CH, Hou Y, Oh W, Chang JW, Jeun SS: Therapeutic effects of human umbilical cord blood-derived mesenchymal stem cells after intrathecal administration by lumbar puncture in a rat model of cerebral ischemia. Stem Cell Res Ther 2011, 2:38.

21. Lin YC, Ko TL, Shih YH, Lin MY, Fu TW, Hsiao HS, Hsu JY, Fu YS: Human umbilical mesenchymal stem cells promote recovery after ischemic stroke. Stroke 2011, 42:2045-2053.

22. Lobel DA, Hadman PR, Sanberg PR, Borlongan CV: Early intracerebral and intra-arterial transplantation of human umbilical cord blood cells into an ischemic rat brain model. Exp Neurol 2003, 181:97.

23. Taguchi A, Soma T, Tanaka J, Kanda T, Nishimura H, Yosikawa H, Tsukamoto Y, Fujimori Y, Stern DM, Naritomi H, Matsuyama T: Administration of CD34+ cells after stroke enhances neurogenesis via angiogenesis in a mouse model. J Clin Invest 2004, 114:330-338.

24. Vendrame M, Cassadt J, Newcomb J, Butler T, Pennypacker KR, Zigova T, Sanberg PR, Willing AE: Infusion of human umbilical cord blood cells in a rat model of stroke dose dependently rescues behavioral deficits and reduces infarct volume. Stroke 2004, 35:2390-2395.

25. Xiao J, Nan Z, Motooka Y, Low W: Transplantation of a novel cell line population of umbilical cord blood stem cells ameliorates neurological deficits associated with ischemic brain injury. Stem Cell Dev 2005, 14:722-733

26. Makinen S, Kekarainen T, Nystedt J, Liimatainen T, Huhtala T, Narvanen A, Laine J, Jolkkonen J: Human umbilcal cord blood cells do not improve sensorimotor or cognitive outcome following transient middle cerebral artery occlusion in rats. Brain Res 2006, 1123:207-215.

27. Nystedt J, Makinen S, Laine J, Jolkkonen J: Human cord blood CD34+ cells and behavioral recovery following focal cerebral ischemia in rats. Acto Neurobiol Exp (Wars) 2006, 66:293-300.

28. Zawadzka M, Lukasiuk K, Machaj EK, Pojda Z, Kaminska B: Lack of migration and neurological benefits after infusion of umbilical cord blood cells in ischemic brain injury. Acta Neurobiol Exp (Wars) 2009, 69:46-51.

29. Borlongan CV, Hadman M, Sanberg CD, Sanberg PR: Central nervous system entry of peripherally injected umbilical cord blood cells is not required for neuroprotection in stroke. Stroke 2004, 35:2385-3389.

30. Sorg RV, Andres S, Kogler G, Fischer J, Wernet P: Phenotypic and functional comparison of monocytes from cord blood and granulocyte colony-stimulating factor-mobilized apheresis products. Exp Hematol 2001, 29:1289-1294.

31. Mayani H, Lansdorp PM: Biology of human umbilical cord blood-derived hematopoietic stem/progenitor cells. Stem Cells 1998, 16:153-165.

32. Ingram DA, Mead LE, Tanaka H, Meade V, Fenoglio A, Mortell K, Pollok K, Ferkowicz MJ, Gilley D, Yoder MC: Identification of a novel hierarchy of endothelial progenitor cells using human peripheral and umbilical cord blood. Blood 2004, 104:2752-2760.

33. Erices $A$, Conget $P$, Minguell JJ: Mesenchymal progenitor cells in human umbilical cord blood. Br J Haematol 2000, 109:235-242.

34. Flynn A, Barry F, O'Brien T: UC blood-derived mesenchymal stromal cells: an overview. Cytotherapy 2007, 9:717-726.

35. Lee OK, Kuo TK, Chen WM, Lee KD, Hsieh SL, Chen TH: Isolation of multipotent mesenchymal stem cells from umbilical cord blood. Blood 2004, 103:1669-1675.
36. Secco M, Zucconi E, Vieira NM, Fogaca LL, Cerqueira A, Carvalho MD Jazedje T, Okamoto OK, Muotri AR, Zatz M: Multipotent stem cells from umbilical cord: cord is richer than blood! Stem Cells 2008, 26:146-150.

37. Zuba-Surma EK, Klich I, Greco N, Laughlin MJ, Ratajczak J, Ratajczak MZ: Optimization of isolation and further characterization of umbilicalcord-blood-derived very small embryonic/epiblast-like stem cells (VSELs). Eur J Haematol 2010, 84:34-46.

38. Habich A, Jurga M, Markiewicz I, Lukomska B, Bany-Laszewicz U, DomanskaJanik K: Early appearance of stem/progenitor cells with neural-like characteristics in human cord blood mononuclear fraction cultured in vitro. Exp Hematol 2006, 34:914-925.

39. McGuckin CP, Forraz N: Potential for access to embryonic-like cells from human umbilical cord blood. Cell Prolif 2008, 41:31-40.

40. Domanska-Janik K, Buzanska L, Lukomska B: A novel, neural potential of non-hematopoietic human umbilical cord blood stem cells. Int J Dev Biol 2008, 52:237-248.

41. Domanska-Janik K, Habich A, Sarnowska A, Janowski M: Neural commitment of cord blood stem cells (HUCB-NSC/NP): therapeutic perspectives. Acta Neurobiol Exp (Wars) 2006, 66:279-291.

42. Zangiacomi V, Balon N, Maddens S, Tiberghien P, Versaux-Botteri C, Deschaseaux F: Human cord blood-derived hematopoietic and neural-like stem/ progenitor cells are attracted by the neurotransmitter GABA. Stem Cells Dev 2009, 18:1369-1378.

43. Bieback K, Kluter H: Mesenchymal stromal cells from umbilical cord blood. Curr Stem Cell Res Ther 2007, 2:310-323.

44. Wang JF, Wang LJ, Wu YF, Xiang Y, Xie CG, Jia BB, Harrington J, McNiece IK: Mesenchymal stem/progenitor cells in human umbilical cord blood as support for ex vivo expansion of CD34(+) hematopoietic stem cells and for chondrogenic differentiation. Haematologica 2004, 89:837-844.

45. Kim DW, Staples M, Shinozuka K, Pantcheva P, Kang SD, Borlongan CV: Wharton's jelly-derived mesenchymal stem cells: phenotypic characterization and optimizing their therapeutic potential for clinical applications. Int J Mol Sci 2013, 14:11692-11712.

46. Arvidsson A, Collin T, Kirik D, Kokaia Z, Lindvall O: Neuronal replacement from endogenous precursors in the adult brain after stroke. Nat Med 2002, 8:963-970

47. Berger C, Schabitz WR, Wolf M, Mueller H, Sommer C, Schwab S: Hypothermia and brain-derived neurotrophic factor reduce glutamate synergistically in acute stroke. Exp Neurol 2004, 185:305-312.

48. Casanova E, Fehsenfeld S, Mantamadiotis T, Lemberger T, Greiner E, Stewart AF, Schutz G: A CamKIlalpha iCre BAC allows brain-specific gene inactivation. Genesis 2001, 31:37-42.

49. Courtes S, Vernerey J, Pujadas L, Magalon K, Cremer H, Soriano E, Durbec $P$ Cayre M: Reelin controls progenitor cell migration in the healthy and pathological adult mouse brain. PLoS One 2011, 6:e20430.

50. Jin K: Reelin and stroke. In Reelin Glycoprotein: Structure, Biology, and Roles in Health and Disease. Edited by Fatemi SH. New York: Springer; 2008:411-420.

51. Ferrer I, Krupinski J, Goutan E, Martí E, Ambrosio S, Arenas E: Brain-derived neurotrophic factor reduces cortical cell death by ischemia after middle cerebral artery occlusion in the rat. Acta Neuropathol 2001, 101:229-238.

52. Gorski JA, Zeiler SR, Tamowski S, Jones KR: Brain-derived neurotrophic factor is required for the maintenance of cortical dendrites. J Neurosci Res 2003, 23:6856-6865.

53. Seiler A, Schneider M, Forster H, Roth S, Wirth EK, Culmsee C, Plesnila N, Kremmer E, Radmark O, Wurst W, Bornkamm GW, Schweizer U, Conrad M: Glutathione peroxidase 4 senses and translates oxidative stress into 12/ 15-lipoxygenase dependent- and AIF-mediated cell death. Cell Metab 2008, 8:237-248.

54. Ursini F, Maiorino M, Valente M, Ferri L, Gregolin C: Purification from pig liver of a protein which protects liposomes and biomembranes from peroxidative degradation and exhibits glutathione peroxidase activity on phosphatidylcholine hydroperoxides. Biochim Biophys Acta 1982, 710:197-211.

55. Wang Y, Cooke MJ, Lapitsky Y, Wylie RG, Sachewsky N, Corbett D, Morshead CM, Shoichet MS: Transport of epidermal growth factor in the stroke-injured brain. J Control Release 2011, 149:225-235.

56. Won SJ, Kim SH, Xie L, Wang Y, Mao XO, Jin K, Greenberg DA: Reelin-deficient mice show impaired neurogenesis and increased stroke size. Exp Neurol 2006, 198:250-259.

57. Longa EZ, Weinstein PR, Carlson S, Cummins R: Reversible middle cerebral artery occlusion without crainiectomy in rats. Stroke 1989, 20:84-91. 
58. Wang-Fisher $Y$, Divani AA, Prado R, Koetzner L: Surgical models of stroke induced by intraluminal filament implantation. In Manual of Stroke Models in Rats. Edited by Wang-Fischer Y. Boca Raton, FL: CRC Press; 2008:133-158.

59. Jaatinen T, Laine J: Isolation of mononuclear cells from human cord blood by Ficoll-Paque density gradient. In Current Protocols in Stem Cell Biology, Wiley Interscience; John Wiley \& Sons, Inc. Edited by Elefanty A, Gregory R, Patient R, Schlaeger T, Snyder E, Yamashita Y. 2007:2A. 1.1-2A.1.4

60. Newcomb JD, Willing AE, Sanberg PR: Umbilical cord blood cells. In Methods in Molecular Biology, Neural Cell Transplantation, Volume 549. Edited by Scolding NJ, Gordon D. Humana Press; Springer Science Publisher; 2009:119-136.

61. Laitinen A, Nystedt J, Laitinen S: The isolation and culture of human umbilical cord blood derived mesenchymal stem cells under low oxygen conditions: mesenchymal stem cell assays and applications. Methods $\mathrm{Mol}$ Biol 2011, 698:63-73

62. Alamo AL, Melnick SJ: Clinical application of four and five-color flow cytometry lymphocyte subset immunophenotyping. Cytometry 2000, 42:363-370.

63. Keeney M, Gratama JW, Chin-Yee IH, Sutherland DR: Isotype controls in the analysis of lymphocytes and CD34+ stem and progenitor cells by flow cytometry: time to let go! Cytometry 1998, 34:280-283.

64. Roederer M, Rosa SD, Gerstein R, Anderson M, Bigos M, Stovel R, Nozaki T, Parks D, Herzenberg L: 8 color, 10-parameter flow cytometry to elucidate complex leukocyte heterogeneity. Cytometry 1997, 29:328-339.

65. Basford C, Forraz N, McGuckin C: Optimized multiparametric immunophenotyping of umbilical cord blood cells by flow cytometry. Nature Protocols 2010, 5:1337-1346.

66. Stelzer GT, Marti G, Hurley A, McCoy P Jr, Lovett EJ, Schwartz A: U.S.-Canadian consensus recommendations on the immunophenotypic analysis of hematologic neoplasia by flow cytometry: standardization and validation of laboratory procedures. Cytometry 1997, 30:214-230.

67. Markgraf CG, Green EJ, Hurwitz BE, Morikawa E, Dietrich WD, McCabe PM, Ginsberg MD, Schneiderman N: Sensorimotor and cognitive consequences of middle cerebral artery occlusion in rats. Brain Res 1992, 575:238-246.

68. Rogers DC, Campbell CA, Stretton JL, Mackay KB: Correlation between motor impairement and infarct volume after permanent and transient middle cerebral artery occlusion in the rat. Stroke 1997, 28:2060-2066

69. Arac A, Brownell SE, Rothbard JB, Chen C, Ko RM, Pereira MP, Albers GW Steinman L, Steinberg GK: Systemic augmentation of alphaB-crystallin provides therapeutic benefit twelve hours post-stroke onset via immune modulation. Proc Natl Acad Sci U S A 2011, 108:13287-13292.

70. Vogel J, Mobius C, Kuschinsky W, Rosenblum Wl: Early delineation of ischemic tissue in rat brain cryosections by high contrast staining. Stroke J Cereb Circ 1999, 30:1134-1141

71. Kelly S, Bliss TM, Shah AK, Sun GH, Ma M, Foo WC, Masel J, Yenari MA, Weissman IL, Uchida N, Palmer T, Steinberg GK: Transplanted human fetal neural stem cells survive, migrate, and differentiate in ischemic rat cerebral cortex. Proc Natl Acad Sci U S A 2004, 101:11839-11844.

72. Dominici M, Le Blanc K, Mueller I, Slaper-Cortenbach I, Marini FC, Krause DS, Deans RJ, Keating A, Prockop DJ, Horwitz EM: Minimal criteria for defining multipotent mesenchymal stromal cells: The International Society for Cellular Therapy position statement. Cytotherapy 2006, 8:315-317.

73. Kaminska B, Gaweda-Walerych K, Zawadzka M: Molecular mechanisms of neuroprotective action of immunosuppressants: facts and hypotheses. J Cell Mol Med 2004, 8:45-58.

74. Saino O, Taguchi A, Nakagomi T, Nakano-Doi A, Kashiwamura S, Doe N, Nakagomi N, Soma T, Yoshikawa H, Stern DM, Okamura H, Matsuyama T: Immunodeficiency reduces neural stem/progenitor cell apoptosis and enhances neurogenesis in the cerebral cortex after stroke. $J$ Neurosci Res 2010, 88:2385-2397.

75. Willing AE, Lixian J, Milliken M, Poulos S, Zigova T, Song S, Hart C, SanchezRamos J, Sanberg PR: Intravenous versus intrastriatal cord blood administration in a rodent model of stroke. J Neurosci Res 2003, 73:296-307.

76. Li Y, Chen J, Chen XG, Wang L, Gautam SC, Xu YX, Katakowski M, Zhang L, Lu M, Janakiraman N, Chopp M: Human marrow stromal cell therapy for stroke in rat: neurotrophins and functional recovery. Neurology 2002, 59:514-523.

77. Li Y, Chen J, Wang L, Lu M, Chopp M: Treatment of stroke in rat with intracarotid administration of marrow stromal cells. Neurology 2001, 56:1666-1672.
78. Harting MT, Jimenez F, Xue H, Fischer UM, Baumgartner J, Dash PK, Cox CS: Intravenous mesenchymal stem cell therapy for traumatic brain injury. J Neurosurg 2009, 110:1189-1197.

79. Burstein BL, Shum-Tim D, Chiu RC: Systemic and coronary delivery of marrow stromal cells for cellular cardiomyoplasty: advantages and precautions. Basic Appl Myol 2003, 13:7-10.

80. Bieback K, Kern S, Kluter H, Eichler H: Critical parameters for the isolation of mesenchymal stem cells from umbilical cord blood. Stem Cells 2004, 22:625-634.

81. Boltze J, Reich DM, Hau S, Reymann KG, Strassburger M, Lobsien D, Wagner DC, Kamprad M, Stahl T: Assessment of neuroprotective effects of human umbilical cord blood mononuclear cell subpopulations in vitro and in vivo. Cell Transplant 2012, 21:723-737.

82. Chen N, Newcomb J, Garbuzova-Davis S, Davis Sanberg C, Sanberg PR, Willing AE: Human umbilical cord blood cells have trophic effects on young and aging hippocampal neurons in vitro. Aging Dis 2010, 1:173-190.

83. Chen J, Li Y, Katakowski M, Chen X, Wang L, Lu D, Lu M, Gautam SC, Chopp $\mathrm{M}$ : Intravenous bone marrow stromal cell therapy reduces apoptosis and promotes endogenous cell proliferation after stroke in female rat. J Neurosci Res 2003, 73:778-786.

84. Shen LH, Li Y, Chen J, Zacharek A, Gao Q, Kapke A, Lu M, Raginski K, Vanguri P, Smith A, Chopp M: Therapeutic benefit of bone marrow stromal cells administered 1 month after stroke. J Cereb Blood Flow Metab 2007, 27:6-13.

85. Sharma HS, Nyberg F, Westman J, Alm P, Gordh T, Lindholm D: Brain derived neurotrophic factor and insulin like growth factor-1 attenuate upregulation of nitric oxide synthase and cell injury following trauma to the spinal cord: an immunohistochemical study in the rat. Amino Acids 1998, 14:121-129.

86. Chen J, Zacharek A, Zhang C, Jiang H, Li Y, Roberts C, Lu M, Kapke A, Chopp $M$ : Endothelial nitric oxide synthase regulates brain-derived neurotrophic factor expression and neurogenesis after stroke in mice. J Neurosci 2005 , 25:2366-2375

87. Hill WD, Hess DC, Martin-Studdard A, Carothers JJ, Zheng J, Hale D, Maeda M, Fagan SC, Carroll JE, Conway SJ: SDF-1 (CXCL12) is upregulated in the ischemic penumbra following stroke: association with bone marrow cell homing to injury. J Neuropathol Exp Neurol 2004, 63:84-96.

88. Miller JT, Bartley JH, Wimborne HJ, Walker AL, Hess DC, Hill WD, Carroll JE: The neuroblast and angioblast chemotaxic factor SDF-1(CXCL12) expression is briefly up regulated by reactive astrocytes in brain following neonatal hypoxic-ischemic injury. BMC Neurosci 2005, 6:63.

89. Rosenkranz K, Kumbruch S, Lebermann K, Marschner K, Jensen A, Dermietzel R, Meier C: The chemokine SDF-1/CXCL12 contributes to the 'homing' of umbilical cord blood cells to a hypoxic-ischemic lesion in the rat brain. J Neurosci Res 2010, 88:1223-1233.

90. Sun L, Lee J, Fine HA: Neuronally expressed stem cell factor induces neural stem cell migration to areas of brain injury. J Clin Invest 2004, 113:1364-1374.

91. Jiang L, Womble T, Saporta S, Chen N, Sanberg CD, Sanberg PR, Willing AE: Human umbilical cord blood cells decrease microglial survival in vitro. Stem Cells Dev 2010, 19:221-228.

92. Kreutzberg GW: Microglia: a sensor for pathological events in the CNS. Trends Neurosci 1996, 19:312-318.

93. Wakabayashi K, Nagai A, Sheikh AM, Shiota Y, Narantuya D, Watanabe T, Masuda J, Kobayashi S, Kim SU, Yamaguchi S: Transplantation of human mesenchymal stem cells promotes functional improvement and increased expression of neurotrophic factors in a rat focal cerebral ischemia model. J Neurosci Res 2010, 88:1017-1025.

94. Harris DT, Schumacher MJ, Locascio J, Besencon FJ, Olson GB, DeLuca D, Shenker L, Bard J, Boyse EA: Phenotypic and functional immaturity of human umbilical cord blood T lymphocytes. Proc Natl Acad Sci U S A 1992, 89:10006-10010.

95. Pimentel-Coelho PM, Rosado-de-Castro PH, da Fonseca LM, Mendez-Otero R: Umbilical cord blood mononuclear cell transplantation for neonatal hypoxic-ischemic encephalopathy. Pediatr Res 2012, 71:464-473.

96. Tang Q, Bluestone JA: The Foxp3+ regulatory $T$ cell: a jack of all trades, master of regulation. Nat Immunol 2008, 9:239-244.

97. Liesz A, Suri-Payer E, Veltkamp C, Doerr H, Sommer C, Rivest S, Giese T, Veltkamp R Regulatory T cells are key cerebroprotective immunomodulators in acute experimental stroke. Nat Med 2009, 15:192-199.

98. Brunstein CG, Miller JS, Cao Q, McKenna DH, Hippen KL, Curtsinger J, Defor $\mathrm{T}$, Levine $\mathrm{BL}$, June $\mathrm{CH}$, Rubinstein $\mathrm{P}$, Rubinstein $\mathrm{P}$, McGlave $\mathrm{PB}$, Blazar BR, Wagner JE: Infusion of ex vivo expanded T regulatory cells in adults 
transplanted with umbilical cord blood: safety profile and detection kinetics. Blood 2011, 117:1061-1070.

99. Cohen JL, Trenado A, Vasey D, Klatzmann D, Salomon BL: CD4(+)CD25(+) immunoregulatory $T$ cells: new therapeutics for graft-versus-host disease. J Exp Med 2002, 196:401-406.

100. Taylor PA, Lees CJ, Blazar BR: The infusion of ex vivo activated and expanded CD4(+)CD25(+) immune regulatory cells inhibits graft-versus-host disease lethality. Blood 2002, 99:3493-3499.

101. Zhao D, Zhang C, Yi T, Lin CL, Todorov I, Kandeel F, Forman S, Zeng D: In vivo-activated $C D 103+C D 4+$ regulatory $T$ cells ameliorate ongoing chronic graft-versus-host disease. Blood 2008, 112:2129-2138.

102. Kern S, Eichler H, Stoeve J, Kluter H, Bieback K: Comparative analysis of mesenchymal stem cells from bone marrow, umbilical cord blood, or adipose tissue. Stem Cells 2006, 24:1294-1301

103. Siegel G, Kluba T, Hermanutz-Klein U, Bieback K, Northoff H, Schafer R: Phenotype, donor age and gender affect function of human bone marrow-derived mesenchymal stromal cells. BMC Med 2013, 11:146.

doi:10.1186/scrt434

Cite this article as: Karlupia et al: Intraarterial transplantation of human umbilical cord blood mononuclear cells is more efficacious and safer compared with umbilical cord mesenchymal stromal cells in a rodent stroke model. Stem Cell Research \& Therapy 2014 5:45.

\section{Submit your next manuscript to BioMed Central and take full advantage of:}

- Convenient online submission

- Thorough peer review

- No space constraints or color figure charges

- Immediate publication on acceptance

- Inclusion in PubMed, CAS, Scopus and Google Scholar

- Research which is freely available for redistribution 